3. (a) A. Kuramata, S. Yamazaki, and K. Nakajima, Extended Abstracts of "22nd Conf. on Solid State Devices and Materials," Jpn. Soc. Appl. Phys., Aug. 22, 1990; (b) R. R. Saxena, J. E. Fouquet, V. M. Sardi, and R. L. Moon, Appl. Phys. Lett., 53, 304 (1988).

4. P. Daniel, H. D. Sarge, and W. Weiner, "Proc. VII Intl. Conf. on Ion Implantation Technology," July 30 , 1990, Surrey, England.

5. (a) D. Kotecki, J. Blouse, C. Parks, and S. Sarkozy, "Proc. MRS Symposium on Chemical Perspectives in Microelectronics," Nov. 26, 1990, Boston, MA; (b) T. E. Tang, in "Technical Digest International Electron Device Conference," IEEE, New York (1989).

6. (a) D. S. Williams and E. A. Dein, This Journal, 134, 657
(1987); (b) W. Kern and R. C. Heim, ibid., 117, 562 (1970).

7. C. L. Keller and P. L. Tucker, "Hazardous Materials Regulations of the Department of Transportation," U.S. Bureau of Explosives, Washington, DC (1987).

8. N. M. Gralenski, Microelectron., Manufact. Test., 10, 2 (1987).

9. W. Kern, W. A. Kurylo, and C. J. Tino, RCA Rev., 46, 117 (1985).

10. M. Shibata, T. Yoshimi, and K. Sugawara, This Journal, 122, 157 (1975).

11. S. M. Sze, "VLSI Technology," McGraw-Hill, Inc., New York (1983).

12. W. Kern, G. L. Schnable, and A. W. Fischer, RCA Rev., 37, 3 (1976).

\title{
Modeling and Optimization of the Step Coverage of Tungsten LPCVD in Trenches and Contact Holes
}

\author{
A. Hasper, J. Holleman, and J. Middelhoek' \\ Faculty of Electrical Engineering, University of Twente, 7500 AE Enschede, The Netherlands \\ C. R. Kleijn and C. J. Hoogendoorn \\ Faculty of Applied Physics, Delft University of Technology, 2600 GA Delft, The Netherlands
}

\section{ABSTRACT}

A model is presented to calculate the step coverage of blanket tungsten low pressure chemical vapor deposition (W-LPCVD) from tungsten hexafluoride $\left(\mathrm{WF}_{6}\right)$. The model can calculate tungsten growth in trenches and circular contact holes, in the case of the $\mathrm{WF}_{6}$ reduction by $\mathrm{H}_{2}, \mathrm{SiH}_{4}$, or both. The step coverage model predictions have been verified experimentally by scanning electron microscopy (SEM). We found that the predictions of the step coverage model for the $\mathrm{H}_{2}$ reduction of $\mathrm{WF}_{6}$ are very accurate, if the partial pressures of the reactants at the inlet of the trench or contact hole are known. To get these reactant inlet partial pressures, we used a reactor model which calculates the surface partial pressures of all the reactants. These calculated surface partial pressures are used as input for our step coverage model. In this study we showed that thermodiffusion plays a very important role in the actual surface partial pressure. In the case where $\mathrm{SiH}_{4}$ was present in the gas mixture trends are predicted very well but the absolute values predicted by the step coverage model are too high. The partial pressure of $\mathrm{HF}$, which is a by-product of the $\mathrm{H}_{2}$ reduction reaction, may be very high inside trenches or contact holes, especially just before closing of the trench or contact hole. We found no influence of the calculated HF partial pressure on the step coverage. Differences between step coverage in trenches and contact holes, as predicted by the step coverage model, were found to agree with the experiments. It is shown that the combination of the step coverage and reactor model is very useful in the optimization towards high step coverage, high throughput, and low WF ${ }_{6}$ flow. We found a perfect step coverage (no void formation) in a $2 \mu \mathrm{m}$ wide and $10 \mu \mathrm{m}$ deep $(2 \times 10 \mu \mathrm{m})$ trench using an average $\mathrm{WF}_{6}$ flow of only $35 \mathrm{sccm}$, at a growth rate of $150 \mathrm{~nm} / \mathrm{min}$. In general, it is shown that the reduction of $\mathrm{WF}_{6} \mathrm{by} \mathrm{SiH}_{4}$ offers no advantages over the reduction by $\mathrm{H}_{2}$ as far as step coverage is concerned.

With the increasing degree of complexity in integrated circuits the aspect ratio of contacts and vias also increases. These geometries require deposition techniques capable of filling submicron high aspect ratio contact holes without void formation. Blanket tungsten, deposited by LPCVD and subsequent back etching (Fig. 1a), is widely used to fill these contacts $(1,2)$. A second possibility is to fill these contacts using a selective deposition scheme (3-11), in order to avoid the need of back etching (see Fig. 1b). An advantage of selective over blanket deposition of tungsten is the economic use of $\mathrm{WF}_{6}$. However, selective deposition of tungsten is only possible when all the contacts are equal in depth (12), which is not always the case (see Fig. 2). Other disadvantages of selective deposition of tungsten are the sensitivity to pretreatments and the nonreproducibility.

To deposit tungsten two reducing agents are widely used. First the $\mathrm{H}_{2}$ reduction reaction of $\mathrm{WF}_{6}$ with the following overall reaction

$$
\mathrm{WF}_{6}+3 \mathrm{H}_{2} \rightarrow \mathrm{W}+6 \mathrm{HF}
$$

Second, the $\mathrm{SiH}_{4}$ reduction reaction of $\mathrm{WF}_{6}$

$$
2 \mathrm{WF}_{6}+3 \mathrm{SiH}_{4} \rightarrow 2 \mathrm{~W}+3 \mathrm{SiF}_{4}+6 \mathrm{H}_{2}
$$

The $\mathrm{H}_{2}$ reduction reaction has shown its excellent step coverage $(1,2)$, but it has some disadvantages compared to the $\mathrm{SiH}_{4}$ reduction reaction such as low and very temperature dependent growth rate (3-5) and rough layers $(1,2,13)$.

${ }^{1}$ Deceased.
The $\mathrm{SiH}_{4}$ reduction reaction however has a high and nearly temperature independent growth rate and results in layers with a small grain size $(1,11,13,14)$. The reactivity of $\mathrm{WF}_{6}$ with silicon in the case of the $\mathrm{SiH}_{4}$ reduction reaction is much less than the $\mathrm{H}_{2}$ reduction reaction. The $\mathrm{WF}_{6}$ reaction with silicon results in the undersirable gouging and encroachment of silicon.

The problem of step coverage has been evaluated in the case of physical vapor deposition (PVD) (24). In that case,
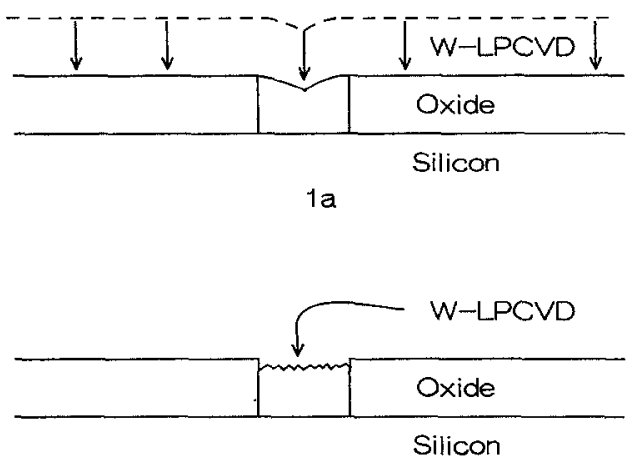

$1 b$

Fig. 1. (a) Blanket deposition of tungsten and subsequent back-etching and (b) selective deposition of tungsten. 


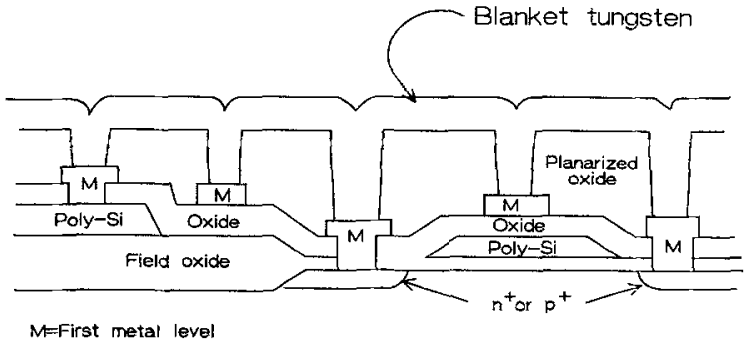

Active Area

Fig. 2. Differences in contact depths that may be present after planarization.

the step coverage is dominated by geometrical sidewall shadowing and surface diffusion. This approach is not applicable for CVD processes. McConica et al. (15) were the first to propose that $W$-LPCVD in circular contact holes could be described by the simultaneous heterogeneous reaction on the side wall and diffusion along the contact hole. Our step coverage model is also based on these assumptions. In this report we extend the model of McConica et al. to a numerical W-LPCVD model for zero- and first-order reactions allowing other geometries (like trenches) and accounting for tungsten growth on the bottom of the geometry in the model boundary conditions.

The step coverage of W-LPCVD has been investigated experimentally as well as theoretically $(1,2,15-23)$. However, using the combination of the output of a reactor model as input for a step coverage model for the reduction of $\mathrm{WF}_{6}$ by $\mathrm{H}_{2}$ and/or $\mathrm{SiH}_{4}$ has not been reported yet. For the $\mathrm{H}_{2}$ reduction reaction an analytical solution of the step coverage can be found in terms of deposition parameters ignoring tungsten growth at the bottom of the features (15). For the $\mathrm{SiH}_{4}$ reduction reaction no such analytical solution can be obtained and numerical methods are necessary.

\section{Theory}

In our study we defined the step coverage as the ratio in percents of the tungsten thickness (a) taken halfway the feature depth and the substrate surface thickness (b) at the moment the feature closes. This definition is shown in Fig. 3 . Thus we obtain $\mathbf{1 0 0 \%}$ step coverage if no void formation occurs.

Knudsen diffusion.-At the pressures $(100 \mathrm{~Pa})$ and temperatures $(673 \mathrm{~K})$ common in W-LPCVD, the mean-free path for the reactants is about $100 \mu \mathrm{m}$. This is much larger than the typical feature diameter. Whenever the mean-free path of the reactants is larger than the diameter of the feature $(25,26)$, Knudsen diffusion is the dominating mechan-

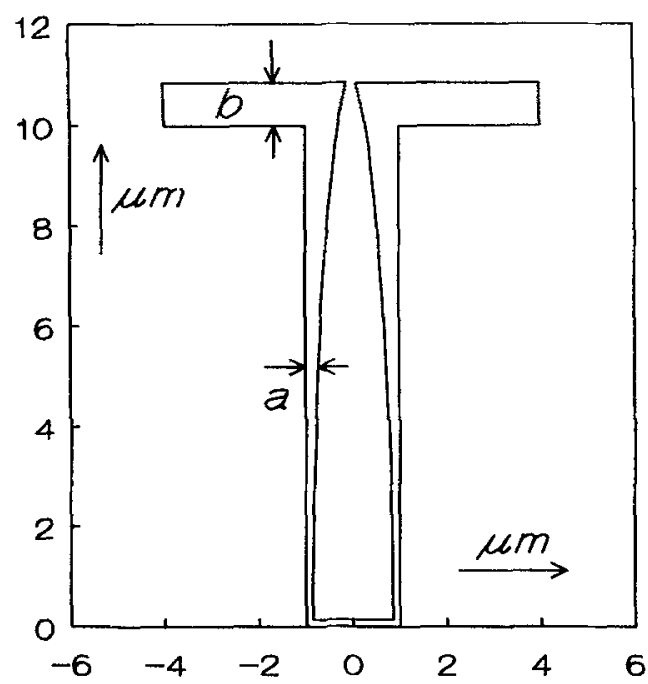

Fig. 3. Schematic sketch of a cross section of a trench or a contact hole. Our definition of the step coverage (S.C.) S. C. $=a / b * 100 \%$. ism for mass transfer. Because the Knudsen diffusion rate is much smaller than bulk diffusion, concentration gradients can occur easily during the growth. The reactants move into the feature by random flights interrupted by collisions and momentary adsorption on the wall. The gas flow is delayed by the wall resistance. This is the so-called Knudsen flow. According to the kinetic theory of gases $(25,26)$, the Knudsen diffusion coefficient can be written as follows.

For a contact hole with radius $r$

$$
D_{\mathrm{k}, \infty}=\frac{2}{3} \cdot r \cdot\left(\frac{8 R T}{\pi M}\right)^{1 / 2}
$$

And for a trench with a width $w$

$$
D_{\mathrm{k}, \infty}=\frac{2}{3} \cdot w \cdot\left(\frac{8 R T}{\pi M}\right)^{1 / 2}
$$

From Eq. [3a] and [3b] the diffusivities of the reactants in infinitely long circular or rectangular tubes are known, however, in practice the aspect ratio is not infinite and the influence of the open end of the feature has to be considered. We have a molecular flow through an open end and a short tube. The tube conductance has to be corrected with a factor depending on the finite length and the influence of the diameter of the feature. This is investigated by Clausing (27), who found a rather complicated expression for this phenomenon. Dushman (26) derived an expression which is an approximation of the so-called Clausing's factor $\left(K^{\prime}\right)$. This approximation is accurate within $10 \%$ compared to the Clausing's factor. The Knudsen diffusion coefficient corrected with this factor for circular contact holes is

$$
D_{\mathrm{k}}=D_{\mathrm{k}, \infty} \cdot K^{\prime}=\frac{2}{3} \cdot r \cdot\left(\frac{8 R T}{\pi M}\right)^{1 / 2} \cdot\left(\frac{1}{1+8 \cdot r / 3 \cdot 1}\right)
$$

For trenches

$$
D_{\mathrm{k}}=D_{\mathrm{k}, \infty} \cdot K^{\prime}=\frac{2}{3} \cdot w \cdot\left(\frac{8 R T}{\pi M}\right)^{1 / 2} \cdot\left(\frac{1}{1+8 \cdot w / 3 \cdot 1}\right)
$$

During the growth, the dimensions of the feature are changing, thus making these diffusion coefficients become time dependent. For the calculation of the step coverage we will use the following two equations.

For contact holes

$$
D_{\mathrm{k}}[r(t), 1(t)]=\frac{2}{3} \cdot r(t) \cdot\left(\frac{8 R T}{\pi M}\right)^{1 / 2} \cdot\left(\frac{1}{1+8 \cdot r(t) / 3 \cdot 1(t)}\right)
$$

For trenches

$$
\begin{aligned}
D_{\mathrm{k}}[w(t), \mathrm{l}(t)]=\frac{2}{3} \cdot w(t) \cdot\left(\frac{8 R T}{\pi M}\right)^{1 / 2} & \\
& \cdot\left(\frac{1}{1+8 \cdot w(t) / 3 \cdot 1(t)}\right)
\end{aligned}
$$

Some remarks have to be made concerning these diffusion coefficients. First, these formulas are derived for tubes without bottoms. In reality molecules can bounce back, but for high aspect ratio features, as studied in this paper, the influence of the bottom will be small. Second, the formulas are derived for features, which are regarded as being constant in cross section across the length. For high aspect ratio trenches and contact holes this is approximately the case during growth.

The hydrogen reduction reaction.-During typical W-LPCVD conditions, the tungsten deposition rate from $\mathrm{H}_{2}$ and $\mathrm{WF}_{6}$, appears to be fully determined by surface chemistry. The overall reaction is given by reaction [1] and the growth rate is given by 
$R_{\mathrm{H}}=c_{1} \cdot\left[p\left(\mathrm{WF}_{6}\right)\right]^{0} \cdot\left[p\left(\mathrm{H}_{2}\right)\right]^{1 / 2} \cdot \exp \left(-E_{\mathrm{A}} / R T\right)$

$$
\text { for } p\left(\mathrm{WF}_{6}\right)>0
$$

$$
R_{\mathrm{H}}=0 \text { for } p\left(\mathrm{WF}_{6}\right)=0
$$

Recently, it was found that the deposition rate is indeed zero-order down to very low pressures of $\mathrm{WF}_{6}(28,38)$. In the literature (3-5, 28-30) $E_{\mathrm{A}}$ is found to be $67-73 \mathrm{~kJ} / \mathrm{mol}$. Based on the extensive experimental set published by Broadbent and Ramiller (3), $E_{\mathrm{A}}$ is taken at $69 \mathrm{~kJ} / \mathrm{mol}$ and $c_{1}=1.7 \times 10^{-4} \mathrm{~mol} \cdot \mathrm{Pa}^{-1 / 2} \cdot \mathrm{cm}^{-2} \cdot \mathrm{s}^{-1}$. These values were shown to be in good agreement with our own experiments. Because $E_{\mathrm{A}}$ and $c_{1}$ were derived from experiments in a hot wall system, the values are not suffering from uncertainties in the wafer temperature.

The silane reduction reaction.- $-\mathrm{WF}_{6}$ can also be reduced by $\mathrm{SiH}_{4}$ (6-10) and other higher order silanes (8). The reaction with $\mathrm{SiH}_{4}$ takes place according to reaction [2] (31). In the literature only a few publications deal with the $\mathrm{SiH}_{4} \mathrm{re}$ duction reaction of $\mathrm{WF}_{6}$. References $(11,14)$ as well as our own observations (see Fig. 4) indicate that the growth rate is first order in the partial pressure of $\mathrm{SiH}_{4}$, and nearly independent of the temperature in the examined region of 523 to $673 \mathrm{~K}$. The deposition rate is also zero order in $\mathrm{WF}_{6}$. The deposition rate of the $\mathrm{SiH}_{4}$ reduction reaction can be written as

$$
\begin{gathered}
R_{\mathrm{s}}=c_{2} \cdot\left[p\left(\mathrm{WF}_{6}\right)\right]^{0} \cdot\left[p\left(\mathrm{SiH}_{4}\right)\right]^{1} \text { for } p\left(\mathrm{WF}_{6}\right)>0 \\
R_{\mathrm{s}}=0 \text { for } p\left(\mathrm{WF}_{6}\right)=0
\end{gathered}
$$

In Eq. [7] $\mathrm{C}_{2}=1.0 \times 10^{-8} \mathrm{~mol} \cdot \mathrm{cm}^{-2} \cdot \mathrm{s}^{-1} \cdot \mathrm{Pa}^{-1}$. In our modeling study Eq. [6] and [7] are used to calculate the growth rate.

Mathematical model of deposition in trenches and contact holes.-The model is based on a one-dimensional mass balance in a contact hole or trench. For this model the following assumptions have to be made; (i) the reaction only takes place on the wall and bottom, (ii) there is no surface diffusion, (iii) the lateral concentration gradients are negligible. With these assumptions the concentration profile in the trench or contact hole can be calculated. Consider a schematic diagram of a volume element $V$ of a trench as represented in Fig. 5

$$
\begin{aligned}
\frac{\partial\left(C_{\mathrm{i}} \cdot V\right)}{\partial t}=\left.\left(\text { Flux }_{\mathrm{in}} \cdot A\right)\right|_{x=x_{1}} & \\
& -\left.\left(\text { Flux }_{\text {out }} \cdot A\right)\right|_{x=x_{2}}-R\left(C_{1}, T\right) \cdot \eta \cdot A_{A}
\end{aligned}
$$

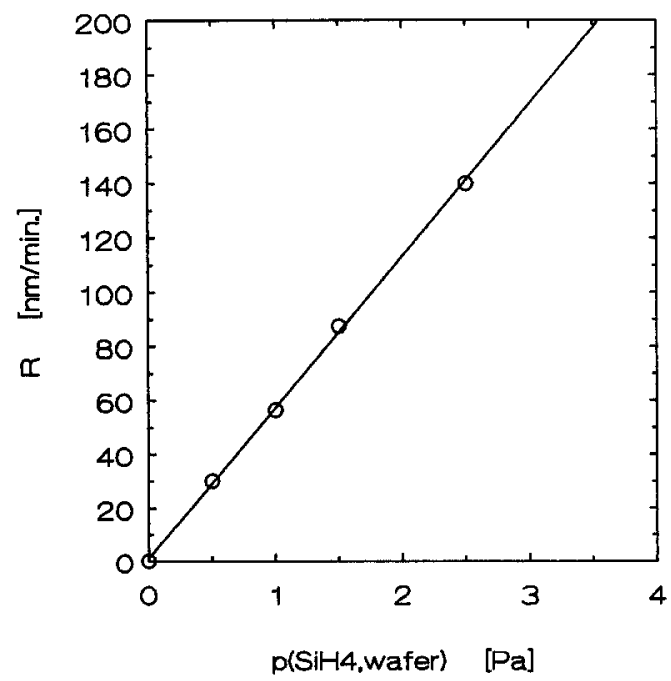

Fig. 4. Growth rate as a function of the partial pressure of $\mathrm{SiH}_{4}$ $\left(T_{\text {wofer }}=673 \mathrm{~K}, P_{\text {tot }}=133 \mathrm{~Pa}, \mathrm{Ar}=1.5 \mathrm{~s} / \mathrm{m}\right.$, and $\left.W_{6}=150 \mathrm{sccm}\right)$.

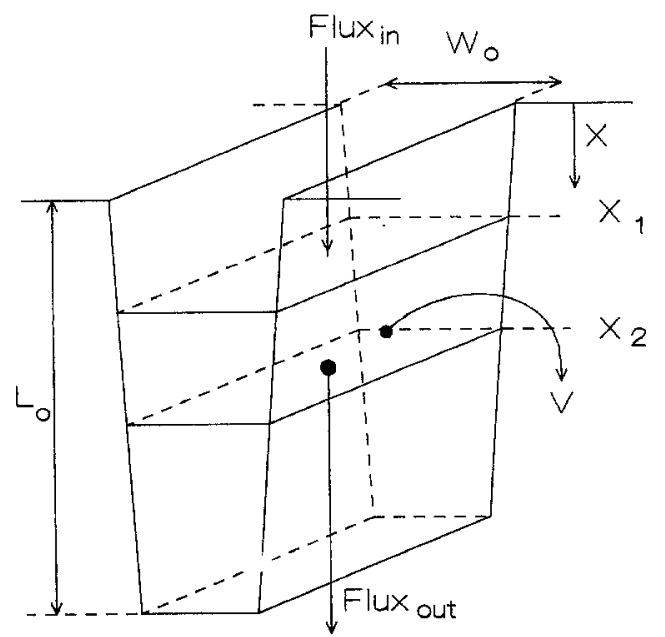

Fig. 5. A schematic drawing of a differential element in a trench.

Here $R\left(C_{\mathrm{i}}, T\right)$ is the molar rate of $\mathrm{WF}_{6}$ disappearance per unit surface area as a function of the local molar concentration $C_{\mathrm{i}}$ and the absolute temperature $T, \eta$ is a stoichiometry constant depending on the chemistry. $A_{\mathrm{A}}$ is the active surface of the volume element $V$ over which the reaction takes place. $A$ is the cross-sectional area of the trench or contact hole. In our step coverage study we considered two geometries

I. A rectangular trench with initial width $W_{0}$ and initial depth $L_{0}$.

II. A circular contact hole with initial radius $R_{0}$ and initial depth $L_{0}$.

For these two geometries this results in the following differential equations for the molar concentrations $C_{\mathrm{i}}$ as given by the following.

For trenches

$$
\frac{\partial\left(C_{\mathrm{i}} \cdot w\right)}{\partial t}=\frac{\partial}{\partial x}\left\{w \cdot D_{\mathrm{k}} \cdot \frac{\partial C_{\mathrm{i}}}{\partial x}\right\}-2 \cdot R\left(C_{\mathrm{i}}, T\right) \cdot \eta
$$

For contact holes

$$
\frac{\partial\left(C_{\mathrm{i}} \cdot r^{2}\right)}{\partial t}=\frac{\partial}{\partial x}\left\{r^{2} \cdot D_{\mathrm{k}} \cdot \frac{\partial C_{\mathrm{i}}}{\partial x}\right\}-2 \cdot R\left(C_{\mathrm{j}}, T\right) \cdot \eta \cdot r
$$

Where the variables $C_{i}, w, r$, and $D_{\mathrm{k}}$ are functions of the position and time. Now from Eq. [9a] and [9b] and according to reaction [1] or/and [2] we can write a set of differential equations for the $\mathrm{WF}_{6}, \mathrm{SiH}_{4}, \mathrm{H}_{2}, \mathrm{SiF}_{4}$, and $\mathrm{HF}$ concentration. For example the differential equation of the $\mathrm{WF}_{6}$ concentration in a trench becomes

$$
\begin{aligned}
\frac{\partial\left\{C_{\mathrm{w}} \cdot w(x, t)\right\}}{\partial t}=\frac{\partial}{\partial x}\{ & \left.w(x, t) \cdot D_{\mathrm{k}}^{\mathrm{w}} \cdot \frac{\partial C_{\mathrm{w}}}{\partial x}\right\} \\
& -2 \cdot\left\{R_{\mathrm{H}}\left(C_{\mathrm{H}}, C_{\mathrm{W}}, T\right)+R_{\mathrm{S}}\left(C_{\mathrm{S}}, C_{\mathrm{W}}\right)\right\}
\end{aligned}
$$

The changing diameters of the features are given by the following differential equations

For trenches

$$
\frac{\partial w(x, t)}{\partial t}=-2 \frac{\left\{R_{\mathrm{S}}\left(C_{\mathrm{W}}, C_{\mathrm{S}}\right)+R_{\mathrm{H}}\left(C_{\mathrm{W}}, C_{\mathrm{H}}, T\right)\right\}}{\rho_{\mathrm{W}}}
$$

For contact holes

$$
\frac{\partial r(x, t)}{\partial t}=-\frac{\left\{R_{\mathrm{S}}\left(C_{\mathrm{W}}, C_{\mathrm{S}}\right)+R_{\mathrm{H}}\left(C_{\mathrm{W}}, C_{\mathrm{H}}, T\right)\right\}}{\rho_{\mathrm{W}}}
$$

By solving the partial differential equations for all reactants, the concentration of $\mathrm{WF}_{6}, \mathrm{SiH}_{4}, \mathrm{H}_{2}, \mathrm{SiF}_{4}$, and $\mathrm{HF}$ can be determined. From these concentrations the growth rate 
at any point in the trench or in the contact hole can be calculated and thus the deposition profile and the step coverage (see Fig. 3).

Suppose that the reactor is operating under steady-state conditions, the concentrations of the reactants at the mouth of the feature are constant. The initial conditions for the partial differential equations, for all $x$, are

$$
\begin{aligned}
& C_{\mathrm{i}}(x, 0)=C_{\mathrm{i}, 0} \\
& r(x, 0)=R_{0} \quad \text { (contact holes) } \\
& w(x, 0)=W_{0} \quad \text { (trenches) } \\
& l(0) \quad=L_{0}
\end{aligned}
$$

The boundary conditions for the concentration $C_{\mathrm{i}}$, for all $t$, are

$$
\begin{gathered}
x=0 \quad C_{\mathrm{i}}(0, t)=C_{\mathrm{i}, \pi} \\
x=L_{0} \quad D_{\mathrm{k}}^{\mathrm{w}} \cdot \frac{\partial \mathrm{Ci}}{\partial x}=-\eta \cdot\left\{R_{\mathrm{H}}\left(C_{\mathrm{W}}, C_{\mathrm{H}}, T\right)+R_{\mathrm{S}}\left(C_{\mathrm{W}}, C_{\mathrm{S}}\right)\right\}
\end{gathered}
$$

The partial differential Eq. [9] and [11] have to be solved numerically with the initial conditions of Eq. [12] and the boundary conditions of Eq. [13]. The boundary conditions at the bottom of the feature are based on the assumption that at the end of the feature the diffusive flux towards the bottom is equal to the consumption of the reactant by the chemical reactions.

The partial differential equations were solved numerically using a fully implicit scheme (32). This implicit scheme is stable even for large time steps. The discretization method we used has a first-order accuracy in time and a second-order accuracy in space. For most of the calculations the total trench depth was divided into 20 equidistant pieces. The grid independence was checked for a representative situation using 50 and 100 grid points. The calculated step coverage obtained on these fine grids differed less than $0.5 \%$ from those obtained on a standard grid of 20 grid points. The time step was chosen to satisfy the requirement that the concentration change between two time steps did not differ more than $0.1 \%$ from the previous calculation. The maximum time step was set to $5 \mathrm{~s}$. We solved the differential equations with full-time dependency. This development differs from $(22,23)$ where these equations were solved using steady- or pseudo steady-state approximations. McConica et al. recently (17) concluded that the steady-or pseudo steady-state solution is only valid for conditions of no significant depletion of the reactants.

In the case of conformal deposition and high aspect ratio features the length of the feature does not change much. In this regard, one should note that for nonconformal feature fillings, the length of the feature is increasing during deposition. In our model we also account for this changing length of the feature during deposition.

\section{Experimental Procedure}

The step coverage experiments of tungsten LPCVD were performed in an ASM cold wall single-wafer reactor, which is designed for handling 8 in. wafers. In our experiments an 8 in. wafer is used as carrier for a 3 in. p-type $10 \Omega \cdot \mathrm{cm}(100)$ wafer. In all the experiments the deposition area was over the whole $8 \mathrm{in}$. wafer. A schematic sketch of the reactor and the gas lines is presented in Fig. 6 . The walls of the reactor chamber are water cooled. The wafer is placed on a graphite susceptor, which is placed on a quartz dome. The susceptor is heated indirectly by a heating element. Gases are injected radially near the top of the reactor perpendicular into a $0.20 \mathrm{~m}$ diam gas tube. This tube is positioned perpendicular to the wafer surface. The purity of the gas sources $\left(\mathrm{WF}_{6}, \mathrm{SiH}_{4}, \mathrm{H}_{2}, \mathrm{Ar}\right.$ ) employed for the experiments was $99.999 \%$.

In cold wall LPCVD reactors the temperature of the wafer is not equal to the temperature of the susceptor, but is related to total pressure, gas composition, coating of the wafer, and the temperature of the susceptor. The temperature of the susceptor could be measured by a series of ther-

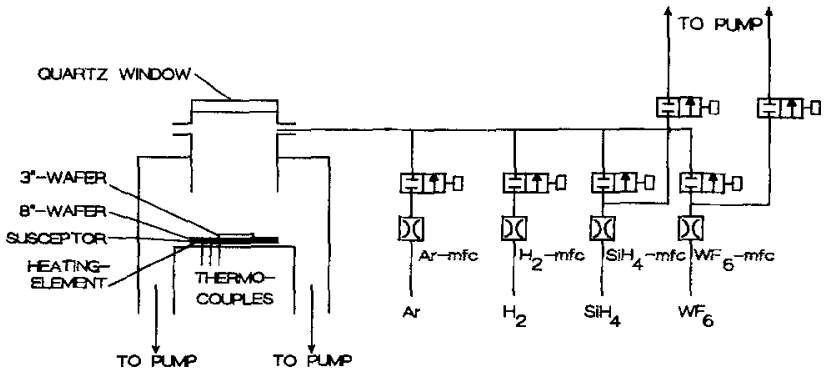

Fig. 6. Schematic sketch of the cold wall reactor and the gas lines.

mocouples. By knowing the temperature of the susceptor, the gas composition, and the total pressure the wafer temperature could be determined from calibration tables with an accuracy of $\pm 5 \mathrm{~K}$. The calibration was done by measuring the temperature of a Si wafer $\left(\mathrm{p}^{+}-0.02 \Omega \cdot \mathrm{cm}\right)$ as a function of the susceptor temperature, the gas composition, and the total pressure. The temperature of the Si wafer $\left(p^{+}-0.02 \Omega \cdot \mathrm{cm}\right)$ was measured with the use of a dual wavelength pyrometer $(2.1$ and $2.3 \mu \mathrm{m})$.

Trenches and circular holes were reactive ion etched (RIE) using a gas mixture of $\mathrm{Cl}_{2}$ and $\mathrm{SiCl}_{4}$. The trenches and circular holes were etched with $\mathrm{SiO}_{2}$ as a mask to a depth of about $10 \mu \mathrm{m}$ and have a diameter ranging from 1 to $4 \mu \mathrm{m}$.

After RIE etching the $\mathrm{SiO}_{2}$ was removed in $\mathrm{HF}$ (1:6). Just before tungsten deposition the wafers received a dip of $30 \mathrm{~s}$ in $1 \%$ HF. Each tungsten deposition was preceded by an in situ deposition of a silicon reduced tungsten film $\left(10 \operatorname{sccm~WF} 6,1.5 \operatorname{sim} \mathrm{Ar}, P_{\mathrm{TOT}}=133 \mathrm{~Pa}, T_{\mathrm{WAFER}}=673 \mathrm{~K}\right)$ of $25 \pm 5 \mathrm{~nm}(13)$.

The thickness of the tungsten films and the step coverage was determined by SEM observations. The use of trenches instead of contact holes as a test vehicle for step coverage is very applicable, because cleaves through trenches can be obtained easily and the trench cleaves expose the real deposition profile. Getting straight cleaves through the middle of contact holes of micron dimensions is hardly possible. Cleaves of contact holes that do not go through the middle, reflect a wrong step coverage. This advantage of trenches as a test vehicle for monitoring step coverage has been described earlier by Schmitz et al. (1).

The step coverage as calculated by the step coverage model were compared with SEM observations. Absolute step coverages as determined by SEM observations have an overall accuracy of $\pm 5 \%$.

The experiments on step coverage used in this study and the deposition parameters are summed up in Appendix A.

\section{Results}

Motivation for using a reactor model.-In order to get precise knowledge of the reactant partial pressures a reactor model is used. The distribution of the reactants are mainly determined by hydrodynamics and transport phenomena. Especially in the case of cold wall single-wafer reactors where deposition rates are high and the walls are cooled, the inlet concentrations do not represent the reactant concentrations just above the wafer surface. These reactant wafer concentrations have to be known in order to calculate the step coverage. The reactor model is used to determine the partial pressures of the reactants just above the wafer surface. These partial pressures are used as input for our step coverage model. In the study $(28,38)$ of growth rates as function of the inlet flows of $\mathrm{WF}_{6}, \mathrm{H}_{2}$, and $\mathrm{Ar}$, it became clear that the inlet concentrations in cold wall reactors do not represent the wafer surface concentrations. The conversion rate, which is often used as criterion for gradientless reactor operation, was shown to be not a good criterion, not even in the case of high gas flows. This study also showed the importance of thermal diffusion phenomena. Due to this thermal diffusion, wafer surface partial pressures of $W_{6}$ will always be lower than the inlet partial pressure. Thermal diffusion causes the relatively heavy $\mathrm{WF}_{6}$ molecules to move away from the hot susceptor. From 
Table I. Comparison between different methods to calculote WFpartial pressures at the wafer surface.

\begin{tabular}{|c|c|c|c|c|}
\hline Exp. & $\begin{array}{c}\text { Conversion } \\
\text { of } \mathrm{WF}_{6}\end{array}$ & $\frac{p\left(\mathrm{WF}_{6}\right)^{\mathrm{a}}}{(\mathrm{Pa})^{-}}$ & $\underset{(\mathrm{Pa})}{p\left(\mathrm{WF}_{6}\right)^{\mathbf{b}}}$ & $\frac{p\left(\mathrm{WF}_{6}\right)^{\mathrm{c}}}{(\mathrm{Pa})^{-}}$ \\
\hline $\begin{array}{r}1 \\
10\end{array}$ & $\begin{array}{l}49 \% \\
13 \%\end{array}$ & $\begin{array}{l}4.66 \\
3.99\end{array}$ & $\begin{array}{l}2.26 \\
3.59\end{array}$ & $\begin{array}{l}1.06 \\
2.00\end{array}$ \\
\hline
\end{tabular}

${ }^{a} p\left(W_{6}\right)$ at wafer surface supposed equal to inlet partial pressure. ${ }^{b}\left(W F_{6}\right)$ at wafer surface supposed equal to outlet partial pressure.

${ }^{c} p\left(\mathrm{WF}_{6}\right)$ at wafer surface calculated by reactor model.

the above it is clear that a reactor model which incorporates thermal diffusion effects is necessary for determining the actual reactant concentrations at the wafer surface. Another advantage of the reactor model is the knowledge of reaction by-product partial pressures just above the wafer surface. In that manner, possible influences of byproducts on the step coverage can be studied. A detailed description of the reactor model that we used can be found in $(28,33,38)$.

As mentioned previously the inlet partial pressure of the reactants, especially $\mathrm{WF}_{6}$, has to be known for accurately predicting the step coverage. For our step coverage model we used inlet partial pressures which were calculated by the reactor model. Other methods, such as accounting for the conversion of the reactants (outlet partial pressure), as used by others $(16,19,23)$ are not accurate, because they do not incorporate thermal diffusion phenomena. In Table I the partial surface pressures of $\mathrm{WF}_{6}$ have been calculated using three different methods. From Table I, we can conclude that the method of calculation for the $\mathrm{WF}_{6}$ partial pressure at the wafer surface can result in large differences, even in the case of low conversion, as in experiment 10 . The reactor model calculations of the $\mathrm{WF}_{6}$ partial pressures are much lower than the other calculation methods. The step coverage model using the wafer surface partial pressure as boundary condition for its calculations will also be influenced by the reactant surface partial pressure.

It must be noted that the reactor model predictions of the $\mathrm{WF}_{6}$ pressure at the wafer surface are relatively sensitive to small errors in the thermal diffusion coefficients, which were obtained from kinetic gas theory. For example, a 25\% increase of the thermal diffusion coefficient led to a decrease in the $\mathrm{WF}_{6}$ surface partial pressure from 1.06 to $0.88 \mathrm{~Pa}$ for experiment 1 and from 2.00 to $1.76 \mathrm{~Pa}$ for experiment 10 . The resulting changes in predicted step coverages for a $2 \times 10 \mu \mathrm{m}$ trench are from 77 to $74 \%$ for experiment 1 and from 82 to $80 \%$ for experiment 10 , respectively.

The hydrogen reduction reaction.-In our step coverage study we did not account for any influence of the by-products on growth rate. For reaction [1] it has been found $(29,34)$ that HF can supress the tungsten growth rate. Others found that $\mathrm{HF}^{\prime}$ did not have more than a dilution effect (35) on deposition rate. It is very difficult to incorporate such influences of by-products in the step coverage modeling because little data are available, and these data are not consistent. In our case using the reactor model we can calculate the partial pressure of HF just above the wafer. If $\mathrm{HF}$ had some influence, the growth rate predicted by the reactor model based on Eq. [6] and the experimental results at different HF partial pressures should contradict. Also the step coverages should be influenced by the in situ generated HF. Especially inside the trenches or contact holes the by-product partial pressures can be very high during growth.

The influence of HF is examined in four experiments, where the HF partial pressure was varied from 1.2 to $12.3 \mathrm{~Pa}$. These varying partial pressures were achieved by changing total flow while maintaining a constant partial pressure of $\mathrm{H}_{2}$. The $\mathrm{HF}$ and $\mathrm{WF}_{6}$ partial pressures were calculated by the reactor model. The results of these four experiments are presented in Table II. From these experiments we see that the influence of HF on step coverage is within the experimental error. From this we may conclude
Table II. Influence of HF on step coverage. In all the experiments the partial pressure of $\mathrm{H}_{2}$ is kept on $110 \mathrm{~Pa}$.

\begin{tabular}{|c|c|c|c|c|c|c|c|}
\hline \multirow[b]{2}{*}{ Exp. } & \multirow{2}{*}{$\begin{array}{c}p\left(\mathrm{WF}_{6}\right) \\
\text { surface } \\
(\mathrm{Pa})\end{array}$} & \multirow{2}{*}{$\begin{array}{c}p(\mathrm{HF}) \\
\text { surface } \\
(\mathrm{Pa})\end{array}$} & \multirow{2}{*}{$\begin{array}{c}\text { Trench } \\
(\mu \mathrm{m})\end{array}$} & \multicolumn{2}{|c|}{$\begin{array}{c}\text { Step } \\
\text { coverage } \\
(\%)\end{array}$} & \multicolumn{2}{|c|}{$\begin{array}{c}\text { Growth rate } \\
(\mathrm{nm} / \mathrm{min})\end{array}$} \\
\hline & & & & $\overline{\operatorname{Exp}}$ & Model & Exp. & Model \\
\hline $\begin{array}{l}1 \\
2 \\
3 \\
4\end{array}$ & $\begin{array}{l}1.04 \\
1.47 \\
1.98 \\
2.38\end{array}$ & $\begin{array}{r}12.30 \\
5.92 \\
2.59 \\
1.20\end{array}$ & $\begin{array}{l}2.0 \times 10 \\
2.6 \times 10 \\
3.2 \times 10 \\
2.4 \times 10\end{array}$ & $\begin{array}{l}73 \\
80 \\
92 \\
89\end{array}$ & $\begin{array}{l}77 \\
86 \\
92 \\
91\end{array}$ & $\begin{array}{l}87.2 \\
77.4 \\
57.4 \\
41.8\end{array}$ & $\begin{array}{l}91.7 \\
83.0 \\
62.2 \\
44.7\end{array}$ \\
\hline
\end{tabular}

that the influence of HF by-product on step coverage is negligible in the examined regime.

In all cases of modeling on the $\mathrm{H}_{2}$ reduction reaction we found that the primary cause of the drop in step coverage is depletion of $W_{6}$ in the trench. Although the reaction is zero order in $\mathrm{WF}_{6}$, the reaction rate still becomes zero when the partial pressure of $\mathrm{WF}_{6}$ becomes zero. This effect of $\mathrm{WF}_{6}$ depletion is shown in Fig. 7 and 8 , where partial pressure profiles of the reactants are shown at several stages during growth, for two typical cases

Figure 7

Figure 8

$$
\begin{aligned}
& -\mathrm{WF}_{6}: \mathrm{H}_{2}=1: 1 \\
& -\mathrm{WF}_{6}: \mathrm{H}_{2}=1: 10
\end{aligned}
$$

In these two cases the partial pressure of $\mathrm{H}_{2}$ at the trench inlet was $17 \mathrm{~Pa}, \mathrm{HF}$ partial pressure was $1.7 \mathrm{~Pa}$, wafer temperature $723 \mathrm{~K}$, resulting in a surface growth rate of about $50 \mathrm{~nm} / \mathrm{min}$. The trenches were $2 \times 10 \mu \mathrm{m}$. From Fig. 7 and 8 we see that the primary cause of the drop in step coverage is $\mathrm{WF}_{6}$ depletion rather than $\mathrm{H}_{2}$ depletion, in spite of the three times higher flux of $\mathrm{H}_{2}$. In general this is because of (i) the higher diffusivity of $\mathrm{H}_{2}$ compared to $\mathrm{WF}_{6}$ (about 12 times), (ii) in almost all cases $\mathrm{H}_{2}$ is available in excess; and (iii) growth rate has only a square root dependence on the $\mathrm{H}_{2}$ partial pressure. Thus considering the $\mathrm{H}_{2}$ partial pressure constant [cf. McConica et al. (15)] during growth does not influence the predicted value of the step coverage much.

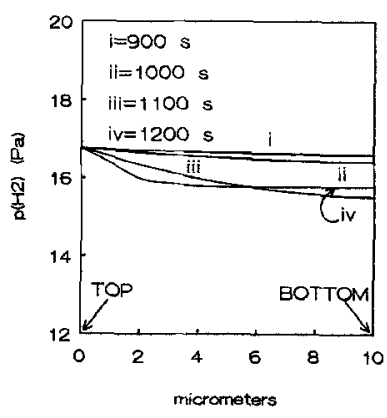

(a)

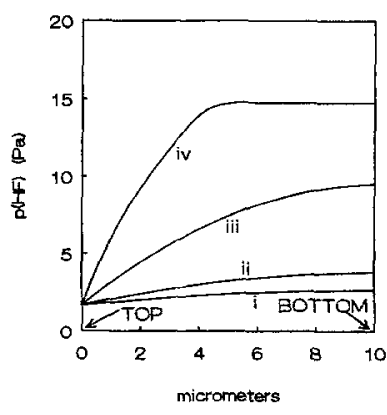

(c)

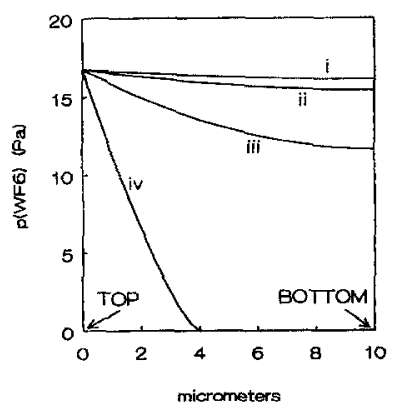

(b)

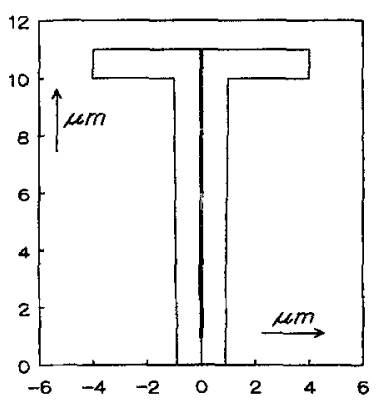

(d)
Fig. 7. Time varying partial pressures profiles in $2 \times 10 \mu \mathrm{m}$ trench for $\mathrm{WF}_{6}: \mathrm{H}_{2}=1: 1(\mathbf{a}-\mathrm{c})$. Partial pressure at the trench inlet were $(\mathbf{a}, \mathbf{b})$ $\mathrm{H}_{2}=\mathrm{WF}_{6}=17 \mathrm{Po}$, (c) $\mathrm{HF}=1.7 \mathrm{Po}, T_{\text {water }}=723 \mathrm{~K}$, resulting in a bulk growth rate of $50 \mathrm{~nm} / \mathrm{min}$. The deposition profile is shown in (d) resulting in a step coveroge of $96 \%$. 


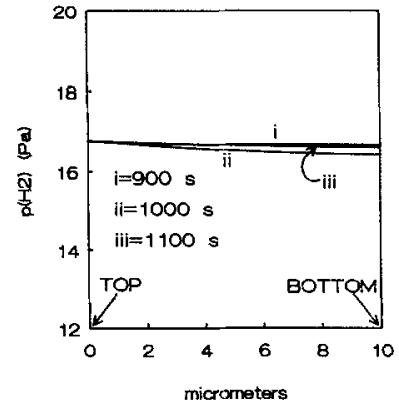

(a)

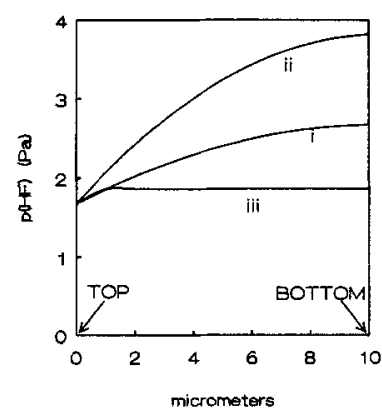

(c)

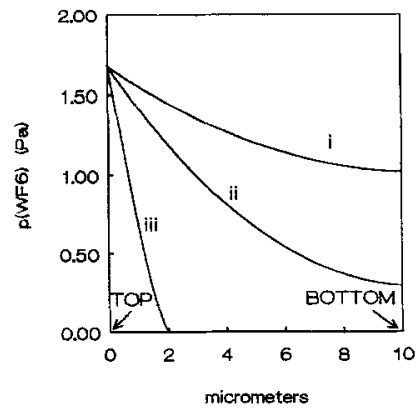

(b)

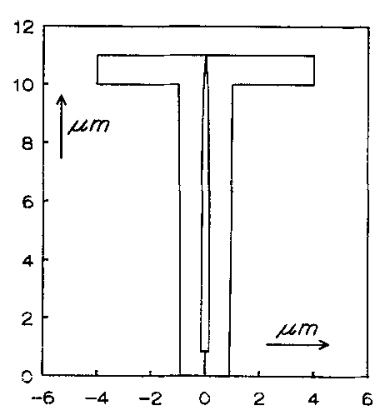

(d)

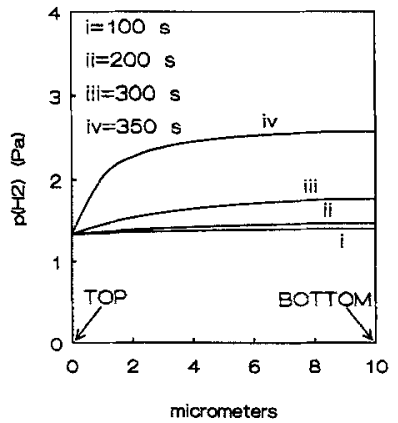

(a)

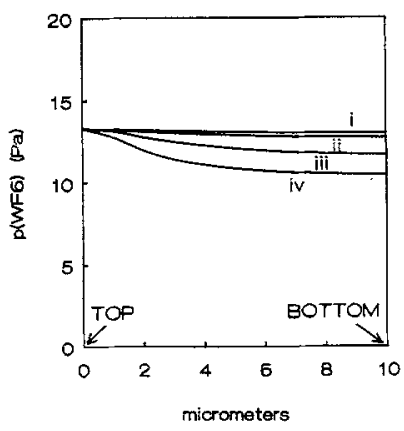

(c)

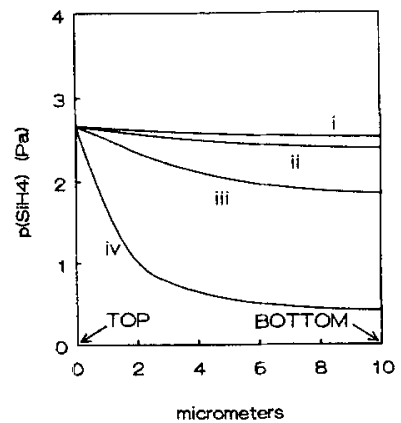

(b)

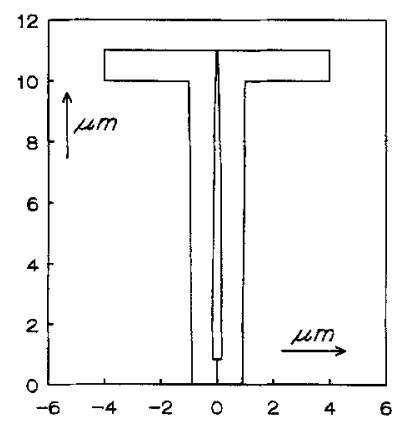

(d)

Fig. 8. $W F_{6}: H_{2}=1: 10$. WF $F_{6}$ partial pressure at trench inlet is re-

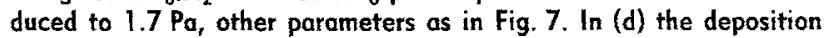
profile is shown, step coverage drops to $86 \%$.

When the growth rate stops due to a lack of $\mathrm{WF}_{6}$, we can see a redistribution of the $\mathrm{H}_{2}$ partial pressure. This effect is shown in Fig. $7 \mathrm{a}$ (compare $t=1100 \mathrm{~s}$ and $t=1200 \mathrm{~s}$ ). The partial pressure of $\mathrm{HF}$ can be very high deep inside the trench or contact hole, as is shown in Fig. 7c and 8c. The resulting modeled deposition profiles for these two cases are shown in Fig. $7 \mathrm{~d}$ and $8 \mathrm{~d}$.

In Fig. 9 the step coverage of all $\mathrm{H}_{2}$ reduction reactions is plotted as a function of the so-called step coverage modulus (SCM), first proposed by McConica et al. (15). This dimensionless number is given by

$$
\mathrm{SCM}=\frac{L_{0}^{2} \cdot R_{\mathrm{H}}}{W_{0} \cdot D_{\mathrm{k}} \cdot C_{\mathrm{W}, 0}}
$$

Figure 9 shows that the model predictions and the experimental values fit well. For simplicity in this figure the changing length during growth is not incorporated, because otherwise a simple S.C. as function of the SCM could not be determined. This makes Fig. 9 only valid for high aspect ratio features. In our experiments, geometries meeting this requirement are used.

The silane reduction reaction.-In the case of the $\mathrm{SiH}_{4}$ reduction of $\mathrm{WF}_{6}$ step coverage is not only determined by

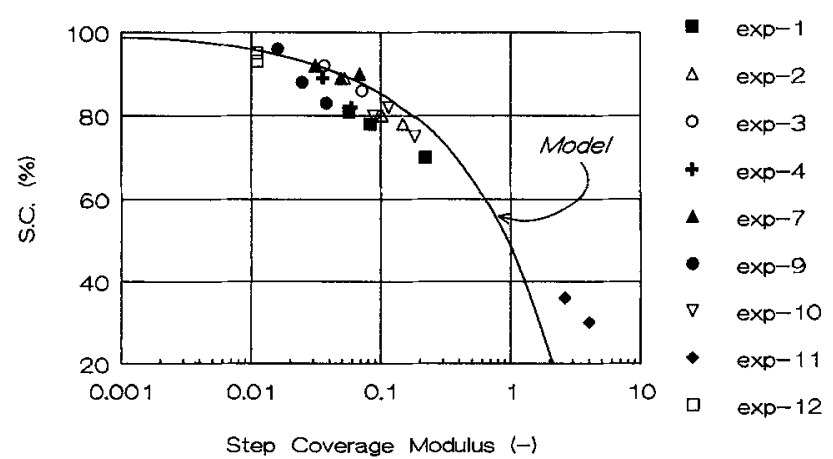

Fig. 9. Step coverage predictions (-) and experiments as a function of the step coverage modulus (SCM).
Fig. 10. Time varying partial pressure profiles in a $2 \times 10 \mu \mathrm{m}$ trench. Trench inlet partial pressures were; $\mathrm{H}_{2}=1.3 \mathrm{~Pa}, \mathrm{SiH}_{4}=$ $2.7 \mathrm{~Pa}$, and $W_{6}=13 \mathrm{~Pa}$. $T_{\text {water }}=673 \mathrm{~K}$, resulting grawth rate 150 $\mathrm{nm} / \mathrm{min}$. (a) $\mathrm{H}_{2}$ partial pressure, (b) $\mathrm{SiH}_{4}$ partial pressure, (c) $\mathrm{WF}_{6}$ partial pressure, and (d) deposition profile, resulting S.C. $=84 \%$.

the $\mathrm{WF}_{6}$ depletion but also by a changing $\mathrm{SiH}_{4}$ partial pressure in the trench or contact hole. In Fig. 10 and 11 partial pressures and deposition profiles are shown for two cases. First, where step coverage is determined by $\mathrm{SiH}_{4}$ depletion

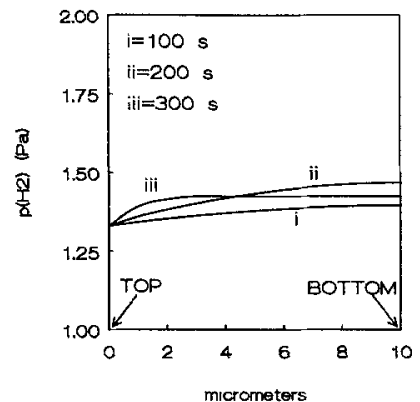

(a)

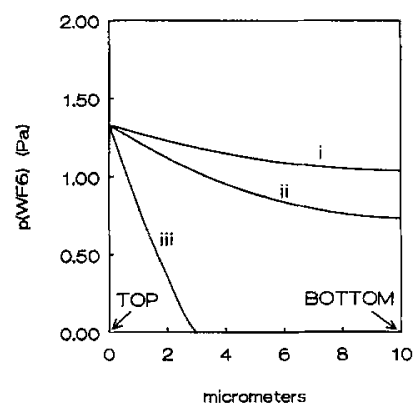

(c)

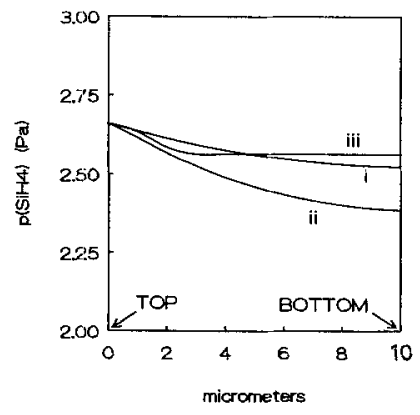

(b)

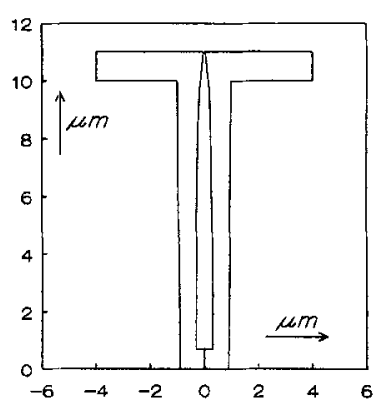

(d)
Fig. 11. Parameters as in Fig. 10, except $W F_{6}$ partial pressure decreased to 1.3 $\mathrm{Pa}$. (a) $\mathrm{H}_{2}$ partial pressure, (b) $\mathrm{SiH}_{4}$ partial pressure, (c) $\mathrm{WF}_{6}$ partial pressure, and (d) deposition profile, resulting S.C. $=71 \%$. 


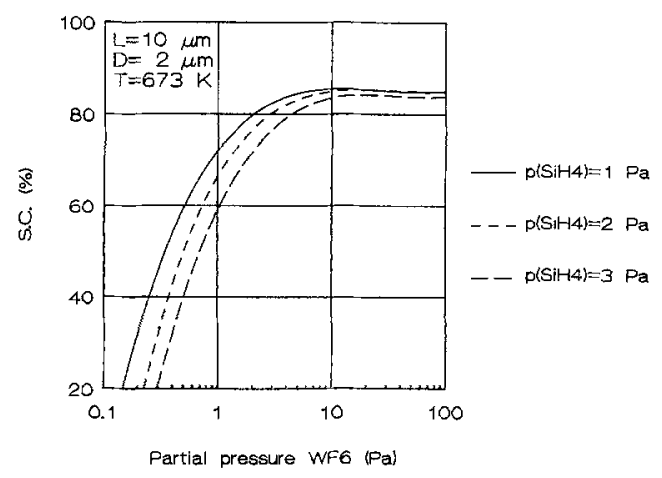

Fig. 12. Step coverage predictions as a function of the partial pressure of $\mathrm{WF}_{6}$ for three different partial pressures of $\mathrm{SiH}_{4}$. (a) $p\left(\mathrm{SiH}_{4}\right)=$ $1 \mathrm{~Pa}(-)$; (b) $p\left(\mathrm{SiH}_{4}\right)=2 \mathrm{~Pa}(---)_{\text {, }}$ and (c) $p\left(\mathrm{SiH}_{4}\right)=3 \mathrm{~Pa}(--)$.

(see Fig. 10) and, second, step coverage is determined by $\mathrm{WF}_{6}$ depletion (see Fig. 11). In both modeling cases the growth rate is maintained at about $150 \mathrm{~nm} / \mathrm{min}$, temperature is $673 \mathrm{~K}$. At the inlet of the feature the partial pressure of $\mathrm{H}_{2}$ is kept at $1.3 \mathrm{~Pa}$ and the $\mathrm{SiH}_{4}$ partial pressure is 2.7 $\mathrm{Pa}$. In Fig. $10 \mathrm{WF}_{6}$ partial pressure is $13 \mathrm{~Pa}$ and in Fig. $11 \mathrm{WF}_{6}$ partial pressure is $1.3 \mathrm{~Pa}$. In Fig. 10 the step coverage is determined by $\mathrm{SiH}_{4}$ depletion and in Fig. 11 by $\mathrm{WF}_{6}$ depletion. We also see an accumulation of $\mathrm{H}_{2}$ in the trench, because $\mathrm{H}_{2}$ is a by-product of the $\mathrm{SiH}_{4}$ reduction reaction. In the case of $\mathrm{SiH}_{4}$ reduction reaction, which is first-order in $\mathrm{SiH}_{4}$, a drop in $\mathrm{SiH}_{4}$ partial pressure directly results in a lower local growth rate. In that case the step coverage is independent on $\mathrm{SiH}_{4}$ partial pressure but only dependent on the geometry of the feature. In Fig. 12 the step coverage predictions as a function of the partial pressure of $\mathrm{WF}_{6}$ at three different partial pressures of $\mathrm{SiH}_{4}$ are shown. From this figure it can be seen that the model predicts step coverages independent of partial pressure of $\mathrm{SiH}_{4}$ provided that the partial pressure of $\mathrm{WF}_{6}$ is sufficiently high. At partial pressures of $\mathrm{WF}_{6}$ lower than about three times the partial pressure of $\mathrm{SiH}_{4}$ the step coverage drops. The reason for this is $\mathrm{WF}_{6}$ depletion rather than $\mathrm{SiH}_{4}$ depletion. Figure 12 also shows that it is fundamentally impossible to obtain a step coverage of $100 \%$ in a $2 \times$ $10 \mu \mathrm{m}$ trench using the $\mathrm{SiH}_{4}$ reduction reaction.

The predicted independency of the step coverage on a changing $\mathrm{SiH}_{4}$ partial pressure at sufficiently high partial pressure of $W^{2}{ }_{6}$ is verified experimentally. The results are shown in Table III. From this table we see that the step coverage as predicted by the model is higher than what is seen experimentally. Until now it is not clear why these predicted values of the step coverage are too high. This may be attributed to the fact that very little kinetic data are available for this $\mathrm{SiH}_{4}$ reduction reaction and the influence of by-products. The influence of $\mathrm{SiF}_{4}$ on the growth rate, as was shown by Schmitz et al. in a single experiment (19), will affect the step coverage to a lower value. Because of the unknown nature and influence of the by-products this is not incorporated in the simulation models.

Experimentally we found no influence of the $\mathrm{SiH}_{4}$ partial pressure on step coverage at sufficiently high $\mathrm{WF}_{6}$ partial pressures. This is in agreement with the model predictions and is a clue that the growth rate of the $\mathrm{SiH}_{4}$ reduction reaction is indeed first order in $\mathrm{SiH}_{4}$. The step coverage model predicts a drop in step coverage when the $\mathrm{WF}_{6}$ par-
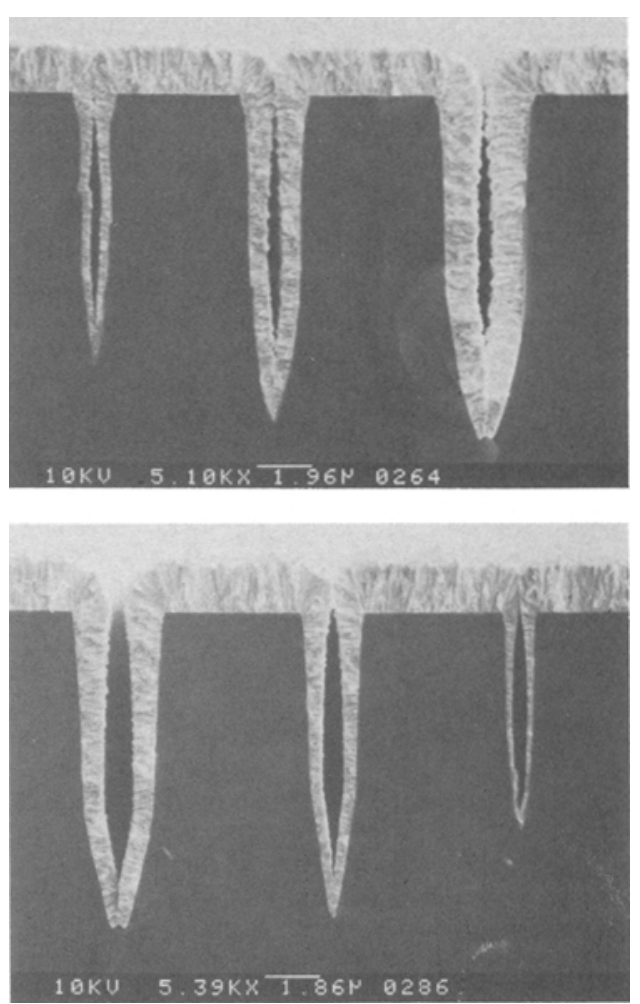

Fig. 13. SEM cross sections for $P\left(\mathrm{SiH}_{4}\right)=1.5 \mathrm{~Pa}, T_{\text {wofer }}=673 \mathrm{~K}$. $\left(a\right.$, top) $p\left(W F_{6}\right)=10 \mathrm{Po}$ and $(\mathrm{b}$, bottom $) p\left(W_{6}\right)=2.4 \mathrm{~Pa}$. Step coverage in (a) is $70 \%$ and in (b) $50 \%$ for the $2 \times 10 \mu \mathrm{m}$ trench.

tial pressure is reduced to a point where step coverage is determined by a lack of $\mathrm{WF}_{6}$. This is illustrated in two SEM cross sections where the surface partial pressure of $\mathrm{SiH}_{4}$ is kept constant at about $1.5 \mathrm{~Pa}$ but the partial pressure of $\mathrm{WF}_{6}$ is reduced from 10 to $2.4 \mathrm{~Pa}$. This resulted in a drop of the step coverage from 70 to $50 \%$ for the $2 \times 10 \mu \mathrm{m}$ trench, see Fig. 13a and $13 \mathbf{b}$.

In the case of the $\mathrm{SiH}_{4}$ reduction reaction of $\mathrm{WF}_{6}$ the model predicts hardly any influence of the temperature. This is verified in three experiments. The results of these experiments are shown in Fig. 14. Although the predicted values are too high the trend is the same.

Comparison of step coverage in trenches and contact holes.-For obtaining experimental step coverage data, trenches are very convenient, because it is much easier to get cleaves through trenches than through contact holes, especially when they are in the range of a few microns. Another advantage of trenches is that they show the real deposition profile. In Fig. 15 a comparison is made between step coverage values predicted in trenches and contact holes of the same diameter depth ratio. This figure is valid (within a few percent) for the $\mathrm{SiH}_{4}$ as well as the $\mathrm{H}_{2}$ reduction reaction.

In one case it was possible to break exactly through a $3.2 \times 10 \mu \mathrm{m}$ contract hole, giving a step coverage of $48 \%$. The trench of $3.2 \times 10 \mu \mathrm{m}$ on the same wafer revealed a step coverage of $76 \%$. This is in very good agreement with Fig. 15 (see dashed line). These cleaves are shown in Fig. $16 \mathrm{a}$ and $16 \mathrm{~b}$.

Table III. Step coverage in $2.2 \times 10 \mu \mathrm{m}$ trenches at different partial pressures of $\mathrm{SiH}_{4}$. In these experiments the wafer temperature was $773 \mathrm{~K}$, total pressure $133 \mathrm{~Pa}$. $1.4 \mathrm{sim}$ argon was used as carrier gas.

\begin{tabular}{|c|c|c|c|c|c|c|}
\hline Exp. & $\begin{array}{c}\text { Conversion } \\
\text { of } W_{F} \\
(\%)\end{array}$ & $\begin{array}{c}p\left(\mathrm{WF}_{6}\right) \\
\text { surface } \\
(\mathrm{Pa})\end{array}$ & $\begin{array}{l}p\left(\mathrm{SiH}_{4}\right) \\
\text { surface } \\
(\mathrm{Pa})\end{array}$ & $\begin{array}{l}\text { Growth } \\
\text { rate } \\
\text { (nm/min) }\end{array}$ & $\begin{array}{c}\text { Step } \\
\text { coverage } \\
\text { experiment } \\
(\%)\end{array}$ & $\begin{array}{c}\text { Step } \\
\text { coverage } \\
\text { model } \\
\text { prediction } \\
(\%)\end{array}$ \\
\hline $\begin{array}{l}14 \\
15 \\
16\end{array}$ & $\begin{array}{l}2 \\
4 \\
6\end{array}$ & $\begin{array}{l}10 \\
10 \\
10\end{array}$ & $\begin{array}{l}0.50 \\
1.00 \\
1.50\end{array}$ & $\begin{array}{l}30.1 \\
56.4 \\
87.5\end{array}$ & $\begin{array}{l}70 \\
70 \\
70\end{array}$ & $\begin{array}{l}84 \\
84 \\
84\end{array}$ \\
\hline
\end{tabular}




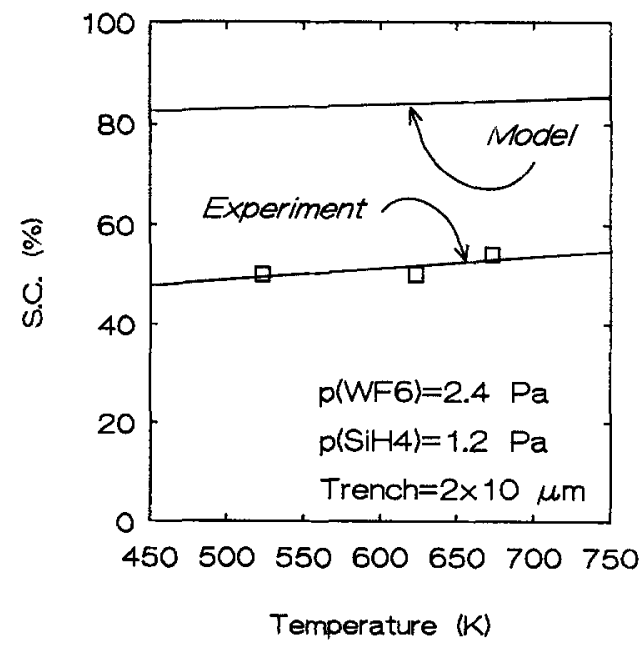

Fig. 14. Influence of temperature on step coverage.

Process optimization.-From the results of the simulations and the experimental verification it is now possible to optimize the step coverage. For this optimization some requirements concerning the $W$-LPCVD process in a single wafer reactor have been made: $(i)$ to get void-free filling of a high aspect ratio contact, step coverage should be $95 \%$ in a feature with an aspect ratio of 5 , (ii) for a throughput of 10 wafers $/ h$, the growth rate should be $150 \mathrm{~nm} / \mathrm{min}$, (iii) for economic reasons conversion of $\mathrm{WF}_{6}$ should be high and total $\mathrm{WF}_{6}$ flow should be low. With the use of the reactor model and the step coverage model these demands could be fulfilled. If a step coverage of $95 \%$ is required in a feature with aspect ratio of 5 the $\mathrm{SiH}_{4}$ reduction reaction, as we saw before (see Fig. 12), is not suitable. So we have to choose the $\mathrm{H}_{2}$ reduction reaction.

From Eq. [6] we see that we have to increase the partial pressure of $\mathrm{H}_{2}$ and temperature to obtain a high growth rate. With regard to multilevel metallization the maximum temperature is limited to $693 \mathrm{~K}$, but if we increase the growth rate by increasing the $p\left(\mathrm{H}_{2}\right)$, step coverage drops, see Eq. [14]. However, another way to increase $p\left(\mathrm{H}_{2}\right)$ is to increase total pressure $\left[P_{\text {TOT }}=p\left(\mathrm{H}_{2}\right)+p\left(\mathrm{WF}_{6}\right)+p(\mathrm{Ar})\right]$. In that case the $\sqrt{p\left(\mathrm{H}_{2}\right)} / p\left(\mathrm{WF}_{6}\right)$ ratio decreases and so does the step coverage modulus (36), see Eq. [14]. In that way the step coverage improves. With a little adaptation of our reactor it was possible to increase the total pressure to 1330 $\mathrm{Pa}$. In that pressure range diffusion in the trenches and contact holes is still dominated by Knudsen diffusion.

For economic use of $\mathrm{WF}_{6}$, its conversion should be high and the $\mathrm{WF}_{6}$ flow should be low. To fulfill this demand we calculated the partial pressure of $\mathrm{WF}_{6}$ at the wafer surface as function of the $\mathrm{WF}_{6}$ inlet flow at low total flow (see Fig. 17). For a step coverage of at least $95 \%$ in a $2 \times 10 \mu \mathrm{m}$

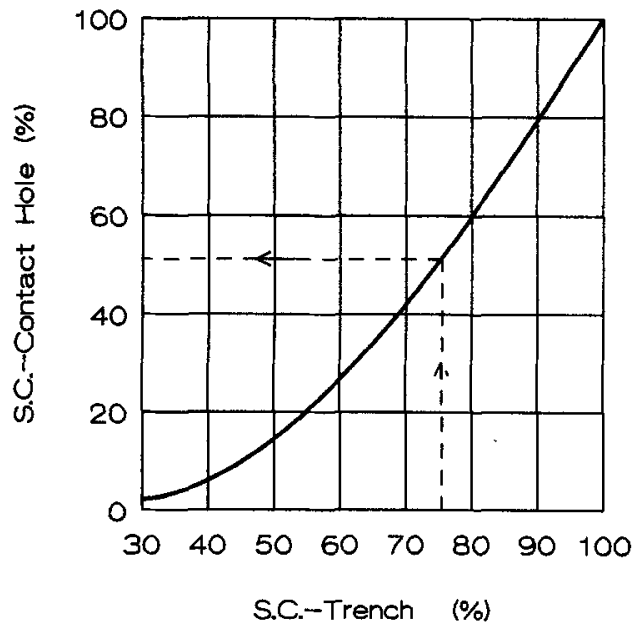

Fig. 15. Comparison of S.C. in trenches and contact holes.
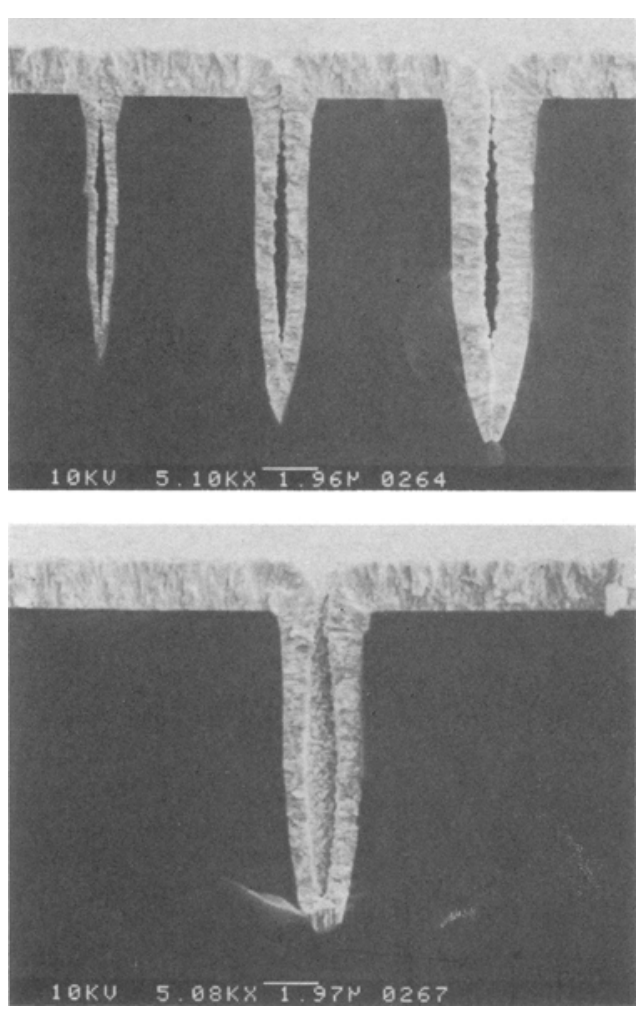

Fig. 16. Cleaves through (a, top) trenches and (b, bottom) a contact hole.

trench and a growth rate of $150 \mathrm{~nm} / \mathrm{min}$ the step coverage model calculates that the partial pressure of $\mathrm{WF}_{6}$ should be greater than $30 \mathrm{~Pa}$, so the $\mathrm{WF}_{6}$ inlet flow has to be greater than $40 \mathrm{sccm}$. To be on the safe side a $\mathrm{WF}_{6}$ inlet flow of 50 sccm is chosen. The result of this experiment can be seen in the SEM cross section in Fig. 18.

During deposition the aspect ratio of a trench or a contact hole is changing from the initial diameter length ratio to infinite. So at the start of the deposition the $\mathrm{WF}_{6}$ partial pressure can be chosen at a lower level than at the end of deposition when the feature is closing. In Fig. 19 we calculated the required $\mathrm{WF}_{6}$ partial pressure at the wafer surface as a function of the deposition time in such a manner that we maintained a $\mathrm{WF}_{6}$ partial pressure greater than zero at the bottom of a $2 \times 10 \mu \mathrm{m}$ trench. From this figure we see that in the beginning the $\mathrm{WF}_{6}$ partial pressure can be lower to ensure a final step coverage of $95 \%$. In Fig. 19 it is also

- = Reactor model

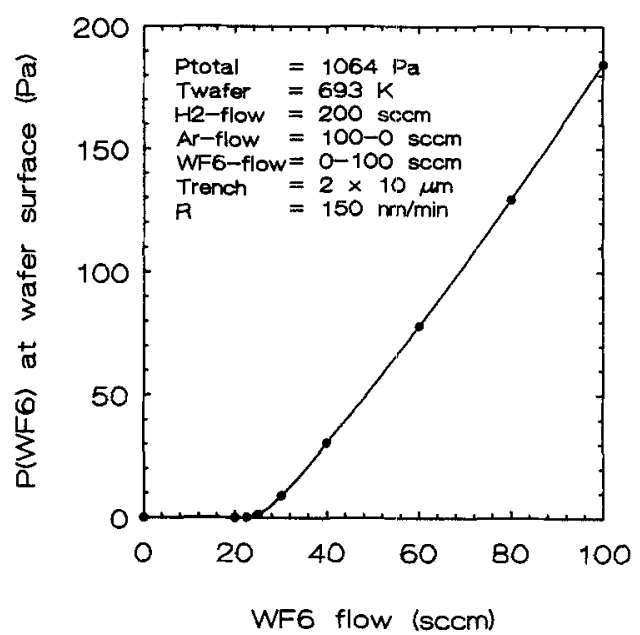

Fig. 17. Partial pressure of $\mathrm{WF}_{6}$ at the wafer surface as a function of the $W_{6}$ inlet flow. 


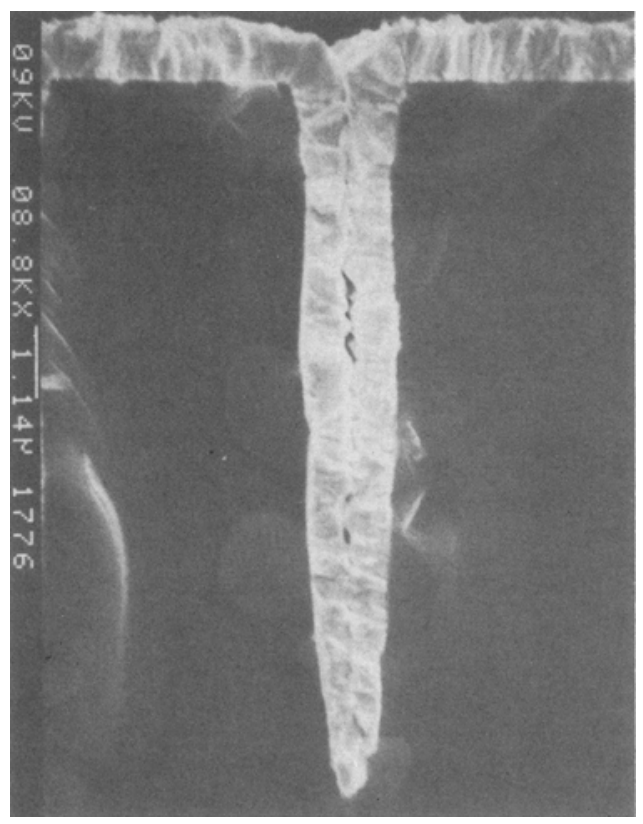

Fig. 18. Cross section of a trench, $P_{\text {total }}=1064 \mathrm{~Pa}, T_{\text {wafer }}=693 \mathrm{~K}$, $\mathrm{H}_{2}=200 \mathrm{sccm}, \mathrm{Ar}=50 \mathrm{sccm}$, and $W_{6}=50 \mathrm{sccm}$. Growth rate is $150 \mathrm{~nm} / \mathrm{min}$.

indicated what the $\mathrm{WF}_{6}$ inlet flow was in the experiment (see dashed line). The result of this experiment with a changing $\mathrm{WF}_{6}$ inlet flow and constant total flow during deposition is shown in the SEM picture of Fig. 20. Here we see that the step coverage of this process is equal to the step coverage found by maintaining a constant $\mathrm{WF}_{6}$ inlet flow of $50 \mathrm{sccm}$; compare Fig. 18 with 20 . As calculated by the reactor model for these two experiments the partial pressure of HF becomes extremely high, about $300 \mathrm{~Pa}$. Note that in spite of this extreme high HF partial pressure we found no influence on step coverage and growth rate. Step coverage as well as growth rate are in agreement with the step coverage and reactor model, respectively.

With this process using the more economic $\mathrm{WF}_{6}$ inlet flow and high total pressure, contact holes of $2 \mu \mathrm{m}$ in diameter and $0.8 \mu \mathrm{m}$ in depth were filled. After RIE back etching in a chlorine containing plasma no void could be detected, see SEM picture in Fig. 21. A conformal step coverage is obtained, otherwise a top view should reveal a hole in the middle of the contact. In Fig. 21 some attack of the RIE plasma on the oxide can be observed.

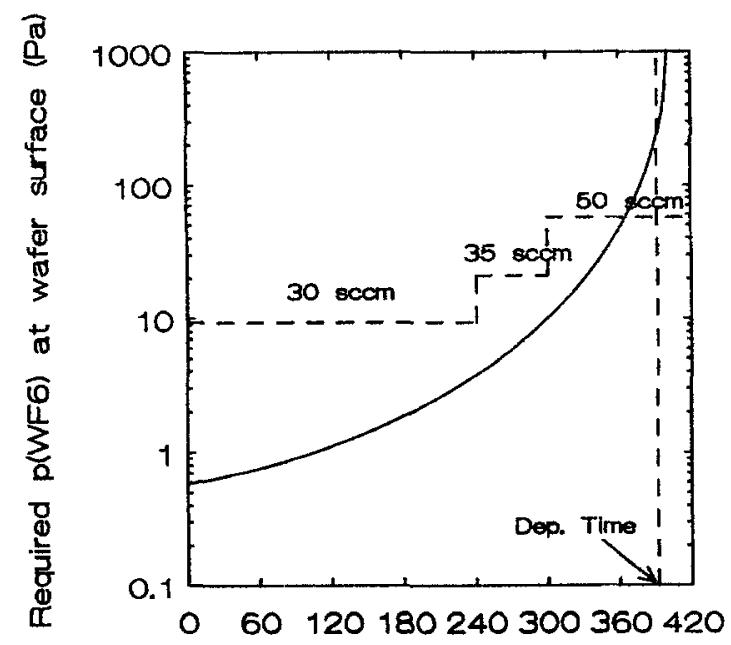

Deposition time (sec)

Fig. 19. Required partial pressure at wafer surface enough to maintain growth on the bottom of a $2 \times 10 \mu \mathrm{m}$ trench as a function of the deposition time. Calculated (-) and experimental (----).

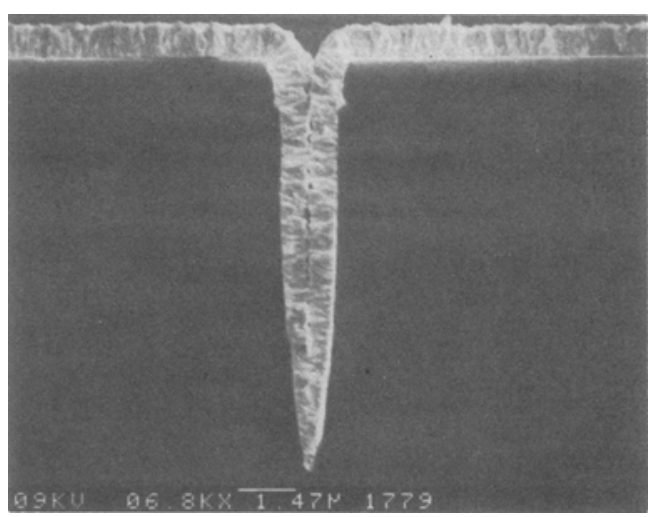

Fig. 20. Cross section of a trench, $P_{\text {total }}=1064 \mathrm{~Pa}, T_{\text {wofer }}=693 \mathrm{~K}$, $\mathrm{H}_{2}=200 \mathrm{sccm}$, Ar varying from 70 to $50 \mathrm{sccm}$, and $W F_{6}$ varying from 30 to $50 \mathrm{sccm}$. Growth rate is $150 \mathrm{~nm} / \mathrm{min}$.

\section{Discussion}

Until now it is not clear why the predicted values of the step coverage in the case of the $\mathrm{SiH}_{4}$ reduction reaction are too high. This may be due to a lack in the knowledge of the true kinetics of the $\mathrm{SiH}_{4}$ reduction reaction and the unknown influence of by-products. However, the trends predicted by the step coverage model were in good agreement with the experiments. From the modeling studies and the experimental observations it is very likely that the $\mathrm{SiH}_{4}$ reduction reaction of $\mathrm{WF}_{6}$ is indeed first order in $\mathrm{SiH}_{4}$.

From a fundamental point of view the $\mathrm{SiH}_{4}$ reduction reaction offers no advantages in terms of step coverage over the $\mathrm{H}_{2}$ reduction reaction. First, the step coverage is worse than the $\mathrm{H}_{2}$ reduction reaction and the step coverage cannot be tuned to a value near $100 \%$ for (sub)micron contact holes. This is because the $\mathrm{SiH}_{4}$ reduction reaction is first order in $\mathrm{SiH}_{4}$. For first-order reactions, step coverage is independent of the partial pressure of the reactant. A second reason for the lower step coverage for the $\mathrm{SiH}_{4}$ reduction reaction is the higher rate constant than the $\mathrm{H}_{2}$ reduction reaction at comparable partial pressures. Another problem with the $\mathrm{SiH}_{4}$ reduction reaction is that the $\mathrm{SiH}_{4} / \mathrm{WF}_{6}$ ratio is extremely important for contact resistance and grain structure $(8,9,11,37)$. Because of the difference of Knudsen diffusivity between $\mathrm{WF}_{6}$ and $\mathrm{SiH}_{4}$ during deposition a change of the ratio of these two reactants can occur easily down to the length of a trench or contact hole. The tungsten of the bottom could contain tungsten silicide which has a much higher resistance. This problem can be avoided by working in an excess of $\mathrm{WF}_{6}$.

For the $\mathrm{H}_{2}$ reduction reaction a good fit of experimental step coverage data and step coverage modeling was found provided we use the reactor model in order to calculate the

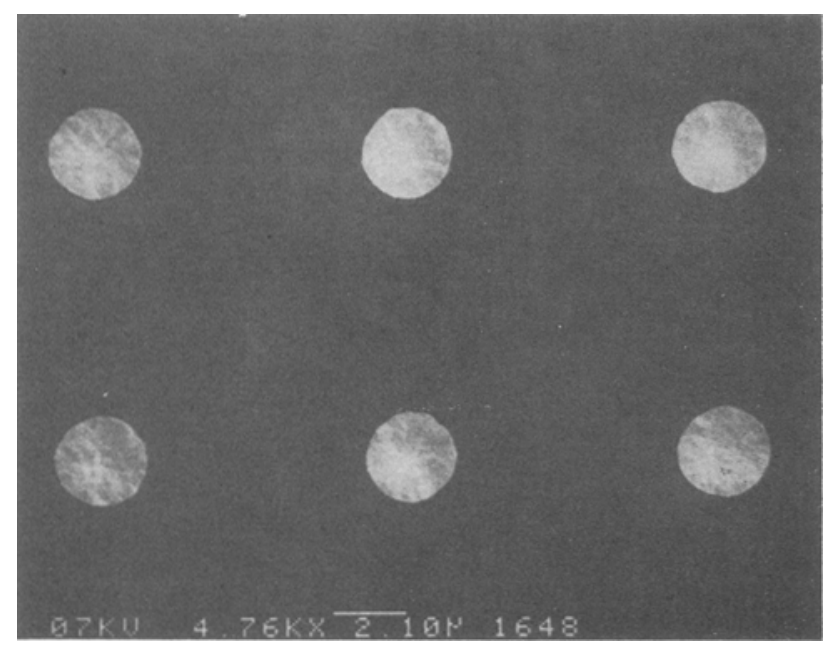

Fig. 21. Contact holes $(2 \times 0.8 \mu \mathrm{m})$ filled with a varying $W F_{6}$ partial pressure and etched back in a chlorinated plasma. 
surface reactant partial pressures. The reactor model showed that keeping reactive areas small and flow rates high is not enough to ensure that the inlet concentrations do represent the wafer surface concentrations. This in contrast to the suggestion of Chatterjee et al. (23). Thermodiffusion strongly affects the reactant concentration profiles in cold wall reactors, especially in the case of a mixture of $\mathrm{WF}_{6}$ and $\mathrm{H}_{2}(28,38)$.

\section{Conclusions}

In the case of the $\mathrm{H}_{2}$ reduction reaction a good agreement between the experimental step coverage data and model is found. The step coverage is determined by the depletion of $\mathrm{WF}_{6}$ in the feature. No influence of $\mathrm{HF}$ is found on step coverage. The step coverage in high aspect ratio features is enhanced by high $\mathrm{WF}_{6}$ partial pressure and low growth rate.

A reactor model is needed to predict true surface concentrations. True concentrations cannot be calculated just by calculating conversion because thermodiffusion plays an important role in the distribution of a gas mixture, especially in the case of a gas mixture containing $\mathrm{WF}_{6}$ and $\mathrm{H}_{2}$. Although high throughput and high step coverage are contradictory goals, we were able to define a process which combines both. Using the step coverage and reactor model a process is obtained with high step coverage, high conversion of $\mathrm{WF}_{6}$, low flow of $\mathrm{WF}_{6}$, and high growth rate.

Process characterization:

$$
\begin{array}{ll}
P_{\text {TOTAL }} & 1064 \mathrm{~Pa} \\
T_{\text {WAFER }} & =693 \mathrm{~K} \\
\mathrm{H}_{2} \text { flow } & =200 \mathrm{sccm} \\
\mathrm{WF}_{6} \text { flow } & =30-50 \mathrm{sccm} \text { (varying) } \\
\text { Ar flow } & =70-50 \mathrm{sccm} \text { (varying) } \\
\text { Growth rate } & =150 \mathrm{~nm} / \mathrm{min} \\
\text { Step coverage } & \geq 95 \% \text { in feature with aspect ratio of } 5 \\
& \text { and uniform over a } 6 \text { in. wafer }
\end{array}
$$

The step coverage of the $\mathrm{SiH}_{4}$ reduction reaction were proven to be independent of the partial pressure of $\mathrm{SiH}_{4}$ at sufficiently high partial pressure of $\mathrm{WF}_{6}$. In that case, the step coverage is only dependent on the aspect ratio of the feature. These experimentally found trends were in agreement with the model predictions, although the absolute predicted values were too high. This may be attributed to a lack in knowledge of the exact kinetics of the $\mathrm{SiH}_{4}$ reduction reaction and the unknown influences of by-products.

Apart from high growth rate and low surface roughness the $\mathrm{SiH}_{4}$ reduction reaction offers no fundamental advantages over the $\mathrm{H}_{2}$ reduction reaction in terms of getting high step coverage.
The step coverage differences as found in trenches and contact holes agree with calculations. Although trends in step coverage found in trenches and contact holes are the same, the absolute values are not.

\section{Acknowledgment}

This work forms part of the "Innovatief Onderzoeks Programma IC Technologies" (Innovating Research Program for IC Technology) and was made possible by the financial

\begin{tabular}{|c|c|}
\hline & LIST OF SYMBOLS \\
\hline$A$ & feature cross-section area, $\mathrm{cm}^{2}$ \\
\hline$A_{\mathrm{A}}$ & active surface area for deposition, $\mathrm{cm}^{2}$ \\
\hline & concentration of any component, $\mathrm{mol} \cdot \mathrm{cm}^{-3}$ \\
\hline$C_{\mathrm{i}}$ & concentration of component $\mathrm{i}, \mathrm{mol} \cdot \mathrm{cm}^{-3}$ \\
\hline$C_{\mathrm{i}, 0}$ & $\begin{array}{l}\text { concentration of component } \mathrm{i} \text { at inlet feature, } \mathrm{mol} \text { - } \\
\mathrm{cm}^{-3}\end{array}$ \\
\hline$c_{1}$ & $\begin{array}{l}\text { hydrogen reduction reaction rate constant, } \mathrm{mol} \cdot \\
\mathrm{Pa}^{-1 / 2} \cdot \mathrm{cm}^{-2} \cdot \mathrm{s}^{-1}\end{array}$ \\
\hline$c_{2}$ & $\begin{array}{l}\text { silane reduction reaction rate constant, } \mathrm{mol} \cdot \mathrm{Pa}^{-1} \text {. } \\
\mathrm{cm}^{-2} \cdot \mathrm{s}^{-1}\end{array}$ \\
\hline$D_{\mathrm{k}}$ & Knudsen diffusivity of any component, $\mathrm{cm}^{2} \cdot \mathrm{s}^{-1}$ \\
\hline$D_{\mathrm{k}, \mathrm{o}}$ & Knudsen diffusivity in infinite geometries, $\mathrm{cm}^{2} \cdot \mathrm{s}^{-1}$ \\
\hline $\begin{array}{l}D_{\mathrm{k}}^{\mathrm{i}} \\
E_{\mathrm{A}}\end{array}$ & $\begin{array}{l}\text { Knudsen diffusivity of component } \mathrm{i}, \mathrm{cm}^{2} \cdot \mathrm{s}^{-1} \\
\text { activation energy } \mathrm{kJ} \cdot \mathrm{mol}^{-1}\end{array}$ \\
\hline $\mathrm{K}$ & factor \\
\hline$L_{0}$ & feature depth, $\mathrm{cm}$ \\
\hline & lepth, cm \\
\hline$M$ & mole weight, $\mathrm{g} \cdot \mathrm{mol}^{-1}$ \\
\hline$p(i)$ & partial pressure of component $\mathrm{i}, \mathrm{Pa}$ \\
\hline & 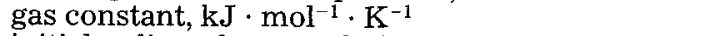 \\
\hline$R_{0}$ & initial radius of cont \\
\hline & variable radius of contact hole, $\mathrm{cm}$ \\
\hline$R_{\mathrm{H}}$ & $\begin{array}{l}\text { deposition rate due to hydrogen reduction reaction, } \\
\mathrm{mol} \cdot \mathrm{cm}^{-2} \cdot \mathrm{s}^{-1}\end{array}$ \\
\hline$R_{\mathrm{S}}$ & $\begin{array}{l}\text { deposition rate due to silane reduction reaction, } \\
\mathrm{mol} \cdot \mathrm{cm}^{-2} \cdot \mathrm{s}^{-1}\end{array}$ \\
\hline S.C & $\begin{array}{l}\text { step coverage based on film thickness at half-fea- } \\
\text { ture depth, } \%\end{array}$ \\
\hline $\mathrm{SC}]$ & rage modulus \\
\hline & ute temperature, $\mathrm{K}$ \\
\hline$l$ & time, $s$ \\
\hline$V$ & \\
\hline & in \\
\hline
\end{tabular}
support from the Netherlands Ministry of Economic Affairs. Bert Otter is also acknowledged for his SEM assistance.

\begin{tabular}{|c|c|c|c|c|c|c|c|c|}
\hline \multirow[b]{2}{*}{$\begin{array}{l}\text { Exp. } \\
(-)\end{array}$} & \multirow[b]{2}{*}{$\begin{array}{c}\mathrm{WF}_{6} \\
(\mathrm{sccm})\end{array}$} & \multirow[b]{2}{*}{$\begin{array}{c}\mathrm{H}_{2} \\
\text { (sccm) }\end{array}$} & \multirow[b]{2}{*}{$\underset{(\mathrm{sccm})}{\mathrm{Ar}}$} & \multirow[b]{2}{*}{$\begin{array}{c}\mathrm{SiH}_{4} \\
(\mathrm{sccm})\end{array}$} & \multirow[b]{2}{*}{$\begin{array}{l}\mathrm{P}_{\mathrm{TOT}} \\
(\mathrm{Pa})\end{array}$} & \multirow[b]{2}{*}{$\begin{array}{c}T_{\text {wafer }} \\
(\mathrm{K})\end{array}$} & \multicolumn{2}{|c|}{ Growth rate } \\
\hline & & & & & & & Exp. & $\begin{array}{l}\text { Model } \\
\text { 1.) }\end{array}$ \\
\hline 1 & 20 & 500 & 46 & 0 & 133 & 703 & 87.2 & 91.7 \\
\hline 2 & 35 & 1000 & 131 & 0 & 133 & 698 & 77.4 & 83.0 \\
\hline 3 & 65 & 2000 & 300 & 0 & 133 & 678 & 57.4 & 62.2 \\
\hline 4 & 125 & 4000 & 639 & 0 & 133 & 663 & 41.8 & 44.7 \\
\hline 7 & 26 & 432 & 425 & 0 & 133 & 683 & 62.7 & 70.3 \\
\hline 8 & 18 & 132 & 435 & 0 & 133 & 683 & 35.2 & 39.8 \\
\hline 9 & 13 & 371 & 49 & 0 & 133 & 648 & 33.3 & 36.6 \\
\hline 10 & 85 & 2400 & 315 & 0 & 133 & 713 & 98.5 & 105.4 \\
\hline 11 & 5 & 2400 & 395 & 0 & 133 & 673 & 41.1 & 24.1 \\
\hline 12 & 50 & 200 & 50 & 0 & 1064 & 693 & 143 & 150.0 \\
\hline 13 & $30-50$ & 200 & $70-50$ & 0 & 1064 & 693 & 135 & 150.0 \\
\hline $13 \mathrm{~b}$ & With be & ling on & See SEl & Fig. 21 & & & - & - \\
\hline 14 & 150 & 0 & 1331 & 70 & 133 & 673 & 140 & 144.9 \\
\hline 15 & 150 & 0 & 1371 & 42 & 133 & 673 & 87.5 & 86.7 \\
\hline 16 & 150 & 0 & 1391 & 28 & 133 & 673 & 56.4 & 57.8 \\
\hline 17 & 150 & 0 & 1411 & 14 & 133 & 673 & 30.1 & 28.8 \\
\hline 18 & 25 & 0 & 500 & 20 & 133 & 673 & 69.0 & 110.0 \\
\hline 19 & 25 & 0 & 500 & 20 & 133 & 523 & 69.0 & 110.0 \\
\hline 20 & 25 & 0 & 500 & 20 & 133 & 623 & 69.0 & 110.4 \\
\hline
\end{tabular}

Manuscript submitted Aug. 24, 1990; revised manuscript received Dec. 18, 1990 .

The University of Twente assisted in meeting the publication costs of this article.

\section{APPENDIX A}

Experiments on step coverage 
$x \quad$ distance along feature length, $\mathrm{cm}$

Greek

$\eta \quad$ stoichiometry constant

$\rho_{\mathrm{w}} \quad$ solid density of deposited tungsten, $\mathrm{mol} \cdot \mathrm{cm}^{-3}$

Subscripts

w tungstenhexafluoride, $\mathrm{WF}_{6}$

$\mathrm{s}$ silane, $\mathrm{SiH}_{4}$

$\mathrm{H}$ hydrogen, $\mathrm{H}_{2}$

$\mathrm{HF}$ hydrogen-fluoride, $\mathrm{HF}$

$\mathrm{SiF}_{4}$ silicon-tetra-fluoride, $\mathrm{SiF}_{4}$

0 at inlet of feature

Superscripts

w tungstenhexafluoride, $\mathrm{WF}_{6}$

s silane, $\mathrm{SiH}_{4}$

$\mathrm{H}$ hydrogen, $\mathrm{H}_{2}$

HF hydrogen-fluoride, $\mathrm{HF}$

$\mathrm{SiF}_{4}$ silicon-tetrafluoride, $\mathrm{SiF}_{4}$

\section{REFERENCES}

1. J. E. J. Schmitz, R. C. Elwanger, and A. J. M. Dijk, in "Tungsten and Other Refractory Metals for VLSI Applications III," V. A. Wells, Editor p. 55, MRS Pub., Pittsburgh (1988).

2. R. Blumenthal and G. C. Smith, ibid., p. 47.

3. E. K. Broadbent and C. L. Ramiller, This Journal, 131, 1427 (1984).

4. E. K. Broadbent and W. T. Stacy, Solid State Technol. 28, 51 (1985).

5. C. M. McConica and K. Krishnamani, This Journal, 133, 2542 (1986).

6. Y. Kushumoto, K. Takakuwa, H. Hashinokuchi, and I. Nakayama, in "Tungsten and Other Refractory Metals for VLSI Applications III," V. A. Wells, Editor p. 103, MRS Pub., Pittsburgh (1988).

7. R. F. Foster, S. Tseng, L. Lane, and K. Y. Ahn, in ibid., p. 69 .

8. T. Ohba, T. Suzuki, T. Hara, Y. Furumura, and K. Wada, in "Tungsten and Other Refractory Metals for VLSI Applications IV," R. S. Blewer, and C. M. McConica, Editors, p. 17, MRS Pub., Pittsburgh (1989).

9. J. E. J. Schmitz, M. J. Buiting, and R. C. Elwanger, ibid., p. 27.

10. K. Y. Ahn, P. M. Fryer, J. M. E. Harper, R. V. Joshi, C. W. Miller, and E. G. Colgan, ibid., p. 35.

11. R. S. Rosler, J. Mendoca, and M. J. Rice, J. Vac. Technol. B, 6, 1721 (1988).

12. R. J. Saia, B. Gorowitz, D. Woodruff, and D. M. Brown, This Journal, 135, 936 (1988).

13. J. Holleman, A. Hasper, and J. Middelhoek, in "Chemical Vapor Deposition of Refractory Metals and Ceramics," T. M. Besman, and B. M. Gallois, Editors, p. 107, MRS Pub., Pittsburgh (1989).

14. J. E. J. Schmitz, A. J. M. van Dijk, and M. W. M. Graef in "Tenth International Conference on Chemical Vapor Deposition," G. W. Cullen, Editor, PV 87-7, p. 625, The Electrochemical Society Softbound Proceedings Series, Pennington, NJ (1988).

15. C. M. McConica and S. Churchill, in "Tungsten and Other Refractory Metals for VLSI Applications III," V. A. Wells, Editor, p. 257, MRS Pub., Pittsburgh (1988).
16. C. M. McConica, S. Chatterjee, and S. Sivaram, Paper presented at Fifth Annual IEEE VLSI Multilevel Interconnection Conference, Santa Clara, CA, 1988.

17. C. M. McConica and A. S. Inamdar, in "Tungsten and Other Refractory Metals for VLSI Applications IV," R.S. Blewer and C. M. McConica, Editors, p. 197, MRS Pub., Pittsburgh (1989).

18. T. S. Cale, F. A. Shemansky, G. B. Raupp, ibid., p. 183.

19. J. E. J. Schmitz, W. L. N. van der Sluys, and A. H. Montree, in "Tungsten and Other Advanced Metals for VLSI/ULSI Applications V," S. S. Wong and S. Furukawa, Editors, p. 117, MRS Pub., Pittsburgh (1990).

20. A. Hasper, C. R. K̇leijn, J. Holleman, and J. Middelhoek, ibid., p. 127.

21. E. J. McInerney, P. Geraghty, and S. Kang, ibid., p. 135.

22. G. B. Raupp and T. S. Cale, Chem. Mater., 1, 207 (1989).

23. S. Chatterjee and C. M. McConica, This Journal, 137, $328(1990)$

24. I. A. Blech, D. B. Fraser and S. E. Haszko, J. Vac. Sci. Technol., 15, 13 (1978); Errata, J. Vac. Sci. Technol., 15, 1856 (1978).

25. M. Knudsen, "The Kinetic Theory of Gases," John Wiley \& Sons, Inc., New York (1950).

26. S. Dushman in "Scientific Foundations of Vacuum Technique," J. M. Lafferty, Editor, John Wiley \& Sons, Inc., New York (1962).

27. P. Clausing, Physica, 9, 65 (1929).

28. C. R. Kleijn, A. Hasper, J. Holleman, C. J. Hoogendoorn, and J. Middelhoek, in "Tungsten and Other Advanced Metals for VLSI/ULSI Applications V," S. S. Wong and and S. Furukawa, Editors, p. 109, MRS Pub., Pittsburgh (1990).

29. Y. Pauleau and Ph. Lami, This Journal, 132, 2779 (1985).

30. W. A. Bryant, ibid., 125, 1534 (1978).

31. M. L. Yu, B. N. Eldridge, and R. V. Joshi in "Tungsten and Other Refractory Metals for VLSI Applications IV," R. S. Blewer and C. M. McConica, Editors, p. 221, MRS Pub., Pittsburgh (1989).

32. W. H. Press, S. A. Flannery, S. A. Teukolski, and W. T. Vetterling, "Numerical Recipes in C," Cambridge University Press (1988)

33. C. R. Kleijn, Th. H, van der Meer, and C. J. Hoogendoorn, This Journal, 136, 3423 (1989).

34. J. F. Berkeley, A. Brenner, and W. E. Reid, ibid., 114, 561 (1976).

35. H. Cheung, in "Proceedings of the 3rd International Conference on Chemical Vapor Deposition," F. A. Glaski, Editor, p. 136, The American Nuclear Society, Hinsdale, IL (1970).

36. J. E. J. Schmitz, A. J. M. van Dijk, J. L. G. Suijker, M. J. Buiting, and R. C. Elwanger, in "Proceedings of the European Workshop on Refractory Metals and Silicides," R. De Keersmaekers and K. Maex, p. 350, North-Holland, Pub. Co., Amsterdam (1989).

37. C. A. van der Jeugd, A. H. Verbruggen, G. J. Leusink, G. C. A. M. Janssen, and S. Radelaar, in "Tungsten and Other Advanced Metals for VLSI/ULSI Applications V," S. S. Wong and S. Furukawa, Editors, p. 267, MRS Pub. Pittsburgh (1990).

38. C. R. Kleijn, A. Hasper, J. Holleman, C. J. Hoogendoorn, and J. Middelhoek, This Journal, 138, 509 (1991). 